\title{
Analysis of the Behavior of Carbon Nanotubes on Cementitious Composites
}

\author{
Jorge Fernandes de Morais, ${ }^{1}$ Assed Naked Haddad, ${ }^{2}$ and Laia Haurie ${ }^{3}$ \\ ${ }^{1}$ Universidade Federal Fluminense, 24210-240 Niterói, RJ, Brazil \\ ${ }^{2}$ Universidade Federal do Rio de Janeiro, 22250-145 Rio de Janeiro, RJ, Brazil \\ ${ }^{3}$ Universitat Politècnica de Catalunya, 08028 Barcelona, Spain \\ Correspondence should be addressed to Jorge Fernandes de Morais; jmorais@yahoo.com
}

Received 27 April 2013; Accepted 11 June 2013

Academic Editors: A. M. Ali, R. Azimirad, J. Bai, Z. Jiang, and Z.-M. Liao

Copyright (c) 2013 Jorge Fernandes de Morais et al. This is an open access article distributed under the Creative Commons Attribution License, which permits unrestricted use, distribution, and reproduction in any medium, provided the original work is properly cited.

\begin{abstract}
Nanotechnology has brought significant innovations in science and engineering. Carbon nanotube has been considered a new and outstanding material in nanoscience field with great potential application in the construction industry. The main objective of this study is to analyze the behavior of cementitious materials produced with the insertion of carbon nanotubes of multiple walls in different concentrations and compare their physic-mechanical properties with plain mortar. This research covers the examination of nanoscale cement products and the use of carbon nanotubes to increase the strength and durability of cementitious composites. Three different ratios of carbon nanotubes have been searched: $0.20,0.40$, and $0.60 \%$. To evaluate the mechanical properties of the samples, destructive and nondestructive tests were carried out to obtain compressive strength, tensile strength by diametrical compression, and dynamic modulus of elasticity as well as to determine their deformation properties. Methods of instrumentation such as scanning electron microscopy and porosity were also used in the analysis of microstructure of the materials. The study presents graphs, tables, and figures describing the behavior of CNT added to mortars samples, allowing a better understanding of the use of this new material in the construction industry.
\end{abstract}

\section{Introduction}

The construction industry is a branch of engineering of great importance, providing the development of various activities for the benefit of civilization and performing significant influence on the organization of society. To cite some examples that prove this relationship between the society and the construction industry, we may think of the infrastructures of water, sewer, and transportation of a country. The activities involved in construction modify the organization of a city over time due to different architectural styles which are formed randomly as well as the distribution and use of those buildings [1].

Cement is a construction material commonly used due to its low cost and high compressive strength, and the enhancement of its performance has been a concern of the research community. Excellence effects performed by nanotechnology have allowed the development of cementitious products of low cost, high performance, and long duration, which may lead to unprecedented uses of these materials in the construction industry $[2,3]$.

The mechanical behavior of cementitious materials depends on structural elements and phenomena occurring in micro- and nanoscale. As a result, nanotechnology may modify the molecular structure of the material, which leads to improving the properties of the bulk of material. Nanotechnology can also improve the mechanical performance, volumetric stability, durability, and sustainability of structure $[2,4]$.

One of the most desired properties of nanomaterials in the construction sector is their capability to confer a mechanical reinforcement to the materials' structure based on cement. Carbon nanotubes (CNT) have superlative mechanical properties and therefore have a promising future when combined with ordinary Portland cement, forming a nanocomposite [5]. CNTs are macromolecules of carbon 
atoms in a periodic hexagonal arrangement with a cylindrical shell shape and categorized as single-walled nanotubes (SWCNTs) and multiwalled nanotubes (MWCNTs). Wrapping a graphene sheet into a seamless cylinder shape conceptualizes the structure of a SWCNT, while MWCNT consists of multiple graphene sheets rolled in on themselves to form a tube shape. CNTs can have diameters ranging from 1 to $100 \mathrm{~nm}$ and lengths up to millimeters [6-9].

The study presented in this paper aims at assessing how carbon nanotubes can affect cement composites in terms of microstructure and physical-mechanical properties [2, 3]. The experimental procedures took place in the laboratories of Universitat Politècnica de Catalunya (UPC), Barcelona, Spain, performing tests as destructive tests, scanning electron microscopy, and porosity measurements [10].

The tests were carried out with mortar samples in cylindrical shape of dimensions $4.4 \mathrm{~cm} \times 8.0 \mathrm{~cm}$ with contents of carbon nanotubes of $0.20 \%, 0.40 \%$, and $0.60 \%$ on the weight of cement to compare their physic-mechanical properties to the equivalent properties of plain mortar without nanotube. The tests were made with the samples at the ages of 3 days, 7 days, and 28 days using a replication factor equal to 3 for each blend. The presentation and analysis of the results of the tests were made with the data processing accomplished based on the theory of "Design of Experiments (DOE)" using the commercial MINITAB program [11].

\section{Experimental Work}

The study was oriented to essentially obtain comparative results between mortar samples with and without carbon nanotubes with no concern with maximization or process improvement. Therefore, it was used in the experiment commercial materials frequently applied in construction, always maintaining the relationship between the components in the preparation of the mortar mixtures and following the same methodology for samples manufacturing and testing [12].

\subsection{Tests Carried Out in Laboratories}

2.1.1. Ultrasound Test. The well-known "Nondestructive Testing methods-NDT" have been object of several researches in laboratories of excellence, worldwide for a long time. Good reasons for adopting these methods may be observed given that they do not affect the appearance or performance of the structure being analyzed. In addition, these tests can be performed in the same place or in a place very close to it and enable a constant monitoring of the structure, allowing evaluation of possible variations over time [13].

Among the NDT methods available, the ultrasound technique may be considered as the most promising one for the evaluation of concrete structures, given that it allows performing homogeneity test of the material. It is possible to perform a total control of the structure, including eventual change of its parameters over time. For example, by analyzing the variation in the propagation speed of an ultrasonic wave

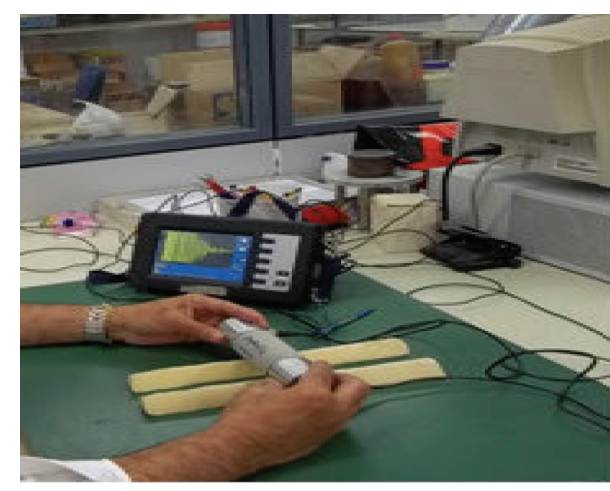

FIGURE 1: Using the method of ultrasound.

one can obtain the degree of compactness of the structure or even detect heterogeneous regions inside the material $[14,15]$.

The ultrasound test was performed according to what was established in the Spanish standard UNE-EN 14579. The test of each specimen consisted in passing through the material a wave of frequency of $55 \mathrm{kHz}$ produced by an ultrasound generator and measuring the corresponding propagation time in microseconds ( $\mu$ s). Figure 1 shows the test.

Using the propagation time, the value of dynamic modulus of elasticity may be obtained by the following equation:

$$
\operatorname{MOE}_{d}=\frac{\left[\rho(1+\mu)(1-2 \mu)\left(L / T_{p}\right)^{2}\right]}{10^{6}(1-\mu)},
$$

where $\mathrm{MOE}_{d}$ is the dynamic modulus of elasticity, $\rho-$ density, $\mu=0,16$-Poisson coefficient, $L$-length of the specimen, and $T_{p}$ - propagation time.

2.1.2. Destructive Tests. The destructive tests were performed to evaluate compression resistance and tensile strength of the cylindrical samples of $4.4 \mathrm{~cm} \times 8.0 \mathrm{~cm}$ in order to compare the behavior of mixtures with CNT with the reference mortar (CN0) without nanotubes [6].

The tests of compressive and tensile strength by diametric compression were performed at the Laboratory of the Department of Materials Science and Metallurgical Engineering, University of Barcelona (UB), at the ages of 3, 7, and 28 days after manufacturing the test pieces in accordance with European Standard UNE-EN 196-1 (2005). A hydraulic press of brand INCOTECNIC PA/MPC-2 was used in this test, controlled by computer, with capacity of 20 tons as illustrated in Figure 2.

For each blend and age, 3 samples (replication factor) were used in the test. The reading provided by the press at the time of rupture of the sample corresponds to the compressive/tensile strength measured in kiloniltons $(\mathrm{kN})$. The compressive stress and tensile stress in megapascal ( $\mathrm{MPa})$ 


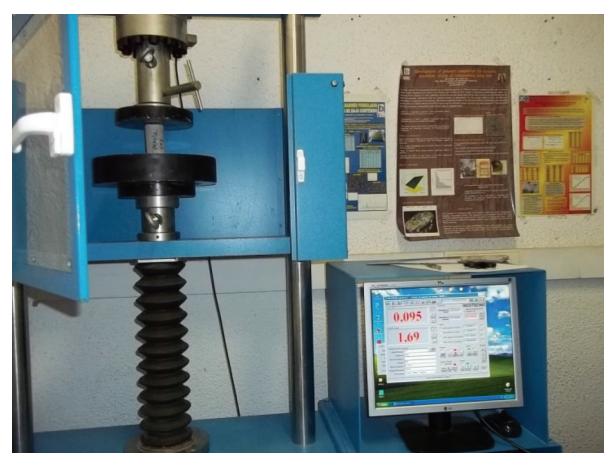

FIgURE 2: Press used for compression and tensile strength tests. Source: Department of Materials Science and Metallurgical Engineering, UB.

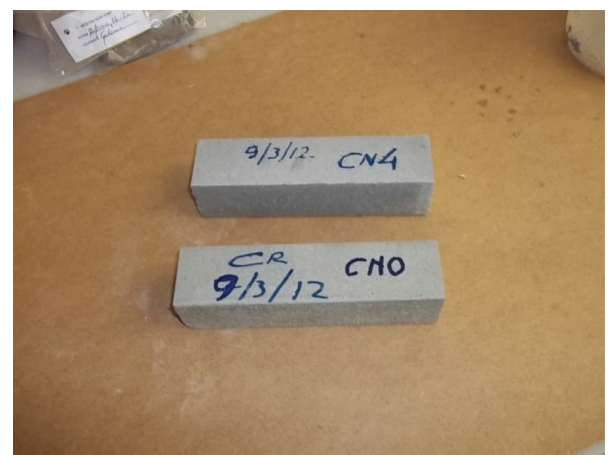

Figure 3: Samples used for the bending test.

were obtained, respectively, with the application of (2) and (3):

$$
\begin{aligned}
\sigma_{c(\mathrm{MPa})} & =\left[\frac{F_{c}(\mathrm{kN})}{S\left(\mathrm{~mm}^{2}\right)}\right] * 1000, \\
\sigma_{t(\mathrm{MPa})} & =\frac{2000 * F_{t}(\mathrm{kN})}{\pi d(\mathrm{~mm}) L(\mathrm{~mm})},
\end{aligned}
$$

where $F_{c}$ is the compressive strength at the time of rupture of the sample, $F_{t}$ is tensile strength by diametric compression at the time of rupture of the samples, and $S, d$, and $L$ correspond, respectively, to the cross-sectional area, diameter, and height of each sample.

Additional tests were made to obtain the flexure curves of the samples. These tests were performed for reasons of feasibility and objectiveness in prismatic specimens of dimensions $4.0 \mathrm{~cm} \times 4.0 \mathrm{~cm} \times 16 \mathrm{~cm}$ (Figure 3 ) and only for the traces $\mathrm{CN} 0$ and $\mathrm{CN} 4$ at the age of 28 days.

In the press, the specimens were positioned, supported at two points on the surface opposite to the application of force, so that the load was applied at the center of the body, as described by the European Standard NP EN 1992-1-1.

2.1.3. Scanning Electronic Microscopy (SEM) Test. The microscopy is a technique used to characterize the microstructure of a material. With the SEM used in this test, the interaction

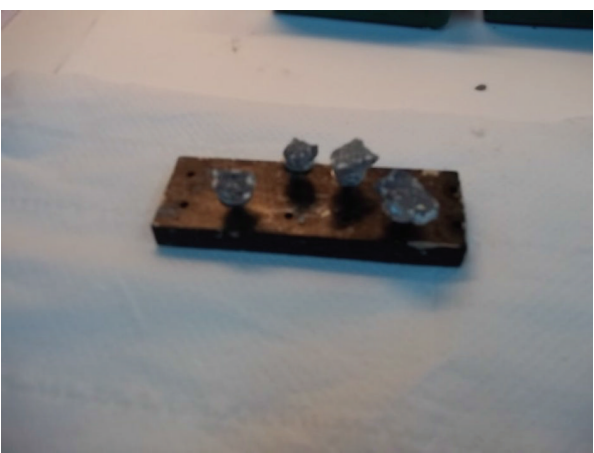

FIgURE 4: Samples used for the SEM test.

of a thin electron beam focused on the microarea or volume analyzed generated a series of signals that could be used to characterize the properties of the sample such as its composition, morphology, and crystallography.

The samples used for this test were obtained with removing material from the disrupted specimens at the age of 28 days and dried in an oven at $100^{\circ} \mathrm{C}$ for 48 hours. The samples were mounted on a support to be coated with a paint based on silver and carbon, to facilitate the detection of a beam produced by an electronic microscope. Figure 4 shows the sample set $\mathrm{CN} 0, \mathrm{CN} 2, \mathrm{CN} 4$, and $\mathrm{CN} 6$ mounted for the test.

2.1.4. Trial to Evaluate the Porosity of Samples. The test was carried out on specimens of mortar CN0, CN2, CN4, and CN6, at the age of 28 days, using a porosimeter located in the Materials Laboratory of the UPC, in accordance with the European Standard UNE-83-309-90 (1990). The samples were obtained by removal of material from the specimens at the age of 28 days disrupted and dried in an oven at $100^{\circ} \mathrm{C}$ for 72 hours. To each mixture two samples (replication factor equal to two) were used, to achieve more significant results.

The procedure consisted of weighing the dried samples $\left(P_{\text {sec }}\right)$ every 24 hours until the weight change became less than $1 \%$. Then the samples were transferred for the vacuum chamber of the porosimeter where they were submerged in water for about 8 hours. After this test, the samples were again weighed on a scale to obtain the weight saturated $\left(P_{\text {sat }}\right)$ and then weighed the specimens suspended in an aqueous solution for determining the hydrostatic weight $\left(P_{\text {hid }}\right)$. The value of the porosity of the samples is determined by (4)

$$
\mathrm{POR}=\left[\frac{\left(P_{\mathrm{sat}}-P_{\mathrm{sec}}\right)}{P_{\mathrm{hid}}}\right] * 100 .
$$

In addition to the porosity of the samples, the test also provided values for the relative density and the apparent 
density of the cementitious composites. These quantities were determined, respectively, by

$$
\begin{gathered}
D_{\text {rel }}=\frac{P_{\text {sec }}}{\left[P_{\text {hid }}-\left(P_{\text {sat }}-P_{\text {sec }}\right)\right]}, \\
D_{\text {ap }}=\frac{P_{\text {sec }}}{P_{\text {hid }}}
\end{gathered}
$$

\subsection{Material and Method}

\subsubsection{Characterization of the Materials}

(i) Cement Portland CEM I 52,5 R UNC-EM 197-1, manufactured by Cimento Molins Industrial S.A. from Barcelona, Spain.

(ii) Sand fine provided by Àrids Catalunya S.A from Barcelona, Spain.

(iii) Potable water supplied by Water and Sanitation Company of Barcelona, Spain.

(iv) Additive super plasticizer polycarboxylate ADVA Flow 401 produced by GRACE Construction Products according to European Standard EN934-2.

(v) Carbon Nanotubes produced and supplied by the Nanomaterials Laboratory of Physics Department of Universidade Federal de Minas Gerais (UFMG) Brazil. They were produced by the method of chemical deposition in vapor phase identified by MWCNT HP2627 and have the following characteristics: type, multiwalled carbon nanotubes (MWCNT), weight, $60 \mathrm{~g}$, purity, $>93 \%$, other carbon structures, $<2 \%$, contaminants, $<5 \%$ of catalyst powder type $\mathrm{MgO}$ Co-Fe, and dimensions, $99 \%$ of the CNT external diameter between $5 \mathrm{~nm}$ and $60 \mathrm{~nm}$ and a length estimated from $5 \mu \mathrm{m}$ e $30 \mu \mathrm{m}$.

2.2.2. Molding of Samples. The specimens for testing were prepared using mortar with different percentages of carbon nanotubes. Four different blends were used to evaluate the behavior of mortars with and without nanotubes:

(1) $\operatorname{mix} 1$ (CN0): cement + sand + water $+1,0 \%$ additive;

(2) $\operatorname{mix} 2(\mathrm{CN} 2)$ : cement + sand + water $+1,0 \%$ additive $+0.20 \% \mathrm{CNT}$;

(3) mix 3 (CN4): cement + sand + water $+1,0 \%$ additive $+0.40 \% \mathrm{CNT}$

(4) mix 4 (CN6): cement + sand + water $+1,0 \%$ additive $+0.60 \%$ CNT.

The European standard EN 196-1 (2005) establishes the standard composition between components for the manufacture of mortar in the following ratios: cement/sand, 1:3 and cement/water 1:1/2. Based on these ratios, plus the CNT and additive, the blends were prepared for manufacturing the specimens for test in the cylindrical shape with dimensions of $4.4 \mathrm{~cm} \times 8.0 \mathrm{~cm}$. As well as what was done with the sand and water, the additive and the percentage of carbon nanotubes in the mixture were taken based on the weight of cement.
The specimens had to be manufactured in batches of six due to the small capacity of the mixer for preparation of mortars associated with the plan of the test in the ages of 3, 7, and 28 days and the shared use of the laboratory of the UPC. The production of mortar and molding of the specimens were performed on the materials laboratory of the "Escola Politècnica Superior d' Edificació of UPC" following the methodology outlined in the following.

(1) Initially cement and sand were weighed on a precision balance gram brand, model ST-4000, maximum capacity of $4,000 \mathrm{~g}$, and accuracy of $\pm 0.1 \mathrm{~g}$. Then the two materials were mixed manually until they reached a homogeneous appearance.

(2) Then, water and additive were weighed on the same balance.

(3) The additive and water were mixed manually in a plastic container for about 5 minutes.

(4) Next, the nanotube was weighed on the same balance for the blends that include this material.

(5) The nanotube was added to water with the additive and mixed by hand for 5 minutes. Then this whole was submitted to the sonication for 60 minutes to obtain a dispersion of nanotubes and a better homogenization of the mixture. For this purpose, we used the equipment ultrasonic P2000 clining qteck Gmbh.

(6) The cement and sand (previously mixed) were accommodated within the mixer, brand Matest model E93, with maximum capacity of $3 \mathrm{~kg}$ together with the mixture of the water, additive, and CNT.

(7) After a mixing time of 15 minutes, the mortar was removed from the mixer for molding the samples. The densification of the samples was made in two layers using a manual vibrating platform. The surface finish of the samples was performed with the aid of a spatula.

(8) After molding, the specimens were kept for 24 hours in a chamber at a temperature of $21.4^{\circ} \mathrm{C}$ and $99 \%$ relative humidity.

(9) After 24 hours, the specimens were demoulded and then were returned to the greenhouse, where they were kept until the test date. Figure 5 shows a batch of six samples ready for testing.

\section{Test Results and Data Analysis}

The following shows the results of tests performed with samples of mortar, with and without carbon nanotubes, as well as the comparative statistical analysis of measurements obtained by making use of the technique of Design of Experiments (DOE) [11].

Due to the limitations found for the tests, the experiments were unable to be performed in random order. The solution adopted was to follow the order of disruption of the samples in their different ages of three, seven, and twenty-eight days. 

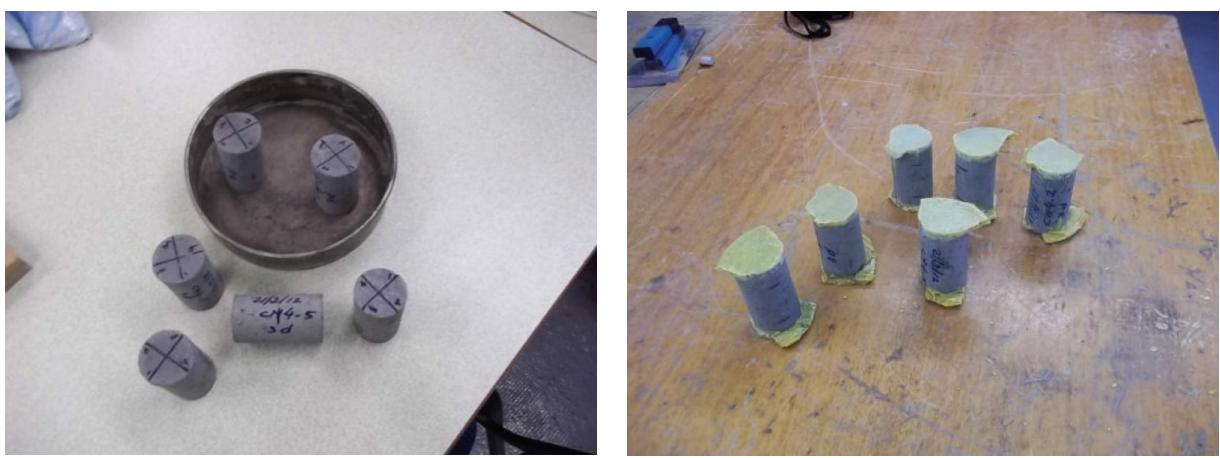

FIGURE 5: Specimens demoulded and ready for testing.

TABLE 1: Multilevel factorial design.

\begin{tabular}{lc}
\hline Factors: 2 & Replicates: 3 \\
Base runs: 12 & Total runs: 36 \\
Base blocks: 1 & Total blocks: 1 \\
Number of levels: 4,3 mean 4 percentages of nanotubes and 3 ages \\
\hline
\end{tabular}

So, the DOE model used in the treatment of the data of this study was the "Comparative Design," not randomized.

The scientific treatment model that was applied to the results obtained from the tests and used in the MINITAB is summarized in Table 1.

Table 2, obtained by running the program MINITAB, shows the sequence of the events with the combination of variables, percentage of nanotubes and age of the samples, and the results of the destructive and nondestructive tests, where $\sigma_{\mathrm{cp}}(\mathrm{MPa})$ represents the values of the compressive strength, $\sigma_{\operatorname{tr}}(\mathrm{MPa})$ represents the values of the tensile strength by diametrical compression, and EMOd (GPa) represents the values of the dynamic modulus of elasticity$\mathrm{MOE}_{d}$.

3.1. Assessment of Resistance of Materials to Efforts of Compression and Tension. The ability to withstand compression forces and tension is an important indicator when evaluating the mechanical strength of cementitious materials. Although the performance of these materials depends on several other factors, it provides a good indication of product quality. Low values of resistance indicate that the mortar or concrete has problems in its structure. These problems may come from the use of the unsuitable materials till a bad formation of its internal structure, due to lack of densification or absence of proper healing, for example.

Tables 3 and 4 summarize the statistical parameters, representing the result of the experiment performed to evaluate the compressive strength and tensile strength by diametric compression of the samples, respectively. The average values of $\sigma_{\mathrm{cp}}$ and $\sigma_{\mathrm{tr}}$ were generated directly by MINITAB, whereas the standard deviation (Dp) and the variance (Var) were calculated, respectively,

$$
\begin{gathered}
\mathrm{Dp}=\left[\frac{\sum\left(X_{i}-X_{m}\right)}{(n-1)}\right]^{1 / 2} \\
\operatorname{Var}=\mathrm{Dp}^{2}
\end{gathered}
$$

where $X_{i}$ represents the value of the readings obtained during the test, $X_{m}$ is the average of readings, and $n$ is the number of samples used in the test. In Table 3, the percentage of gain or reduction was taken in relation to the reference sample CN0.

With the values of $\sigma_{\mathrm{cp}}$ and $\sigma_{\mathrm{tr}}$, inserted in Table 2, the MINITAB program, using the technique of regression analysis, generated the statistical model profiles to the compressive and tensile tests represented, respectively, by the graphics on Figures 6 and 7.

The validation of a model is possibly the most important step in the sequence of statistical model building. The residual plots are used to ensure that the assumptions associated with the ANOVA model are not violated. The ANOVA model assumes that the random errors are independent and normally distributed with the same variance for each treatment.

The normal probability plot is a graphical technique for testing a data distribution model of an experiment. It is estimated, thereby, whether a data set presents or not a Gaussian distribution profile.

It is possible to see from the graphics (a), on both Figures 6 and 7 , that the values of $\sigma_{\mathrm{cp}}$ and $\sigma_{\mathrm{tr}}$ are distributed on concentrated form, almost entirely along the straight line, which leads us to conclude that the model performed by the test has the profile of a normal distribution. This fact is ratified by the histograms (graphics (c)); they are configured with a bell-shaped symmetry, which is evenly distributed around zero, showing that the assumption of normality is likely to be true.

Graphics (b) and (d), on both Figures 6 and 7, depict an experiment with consistent methodology, since the residues are randomly distributed around zero, on a band within $\pm 2 \%$, meaning that there is no deviation in the process. The divergences found on these graphs are the values corresponding 


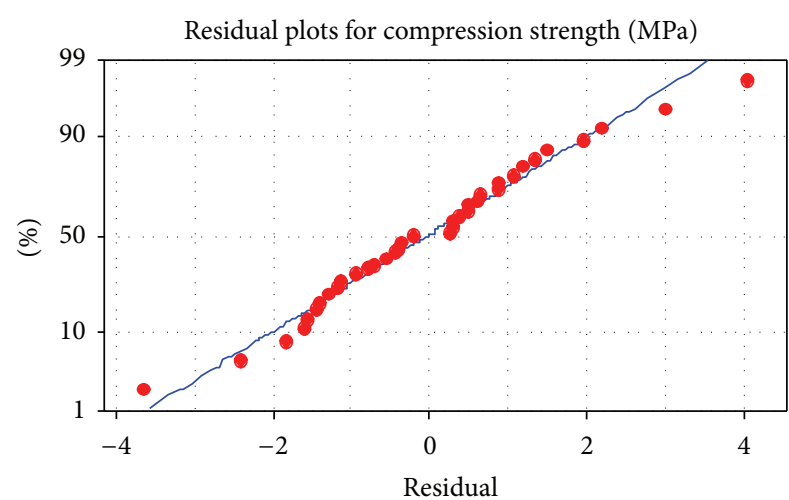

(a) Normal probability plot

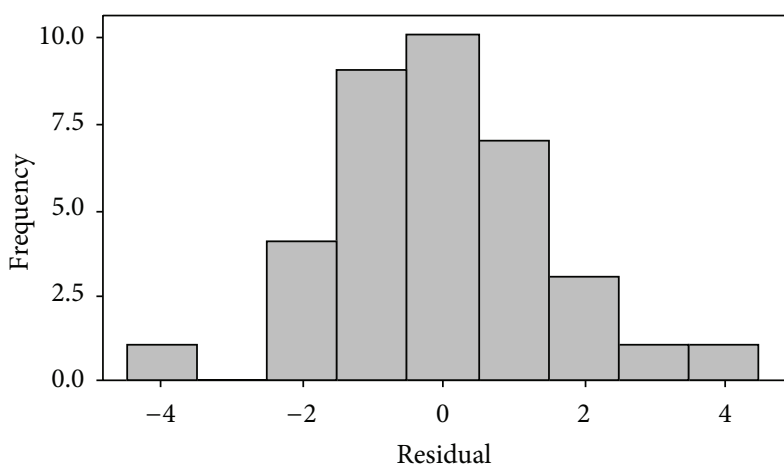

(c) Histogram

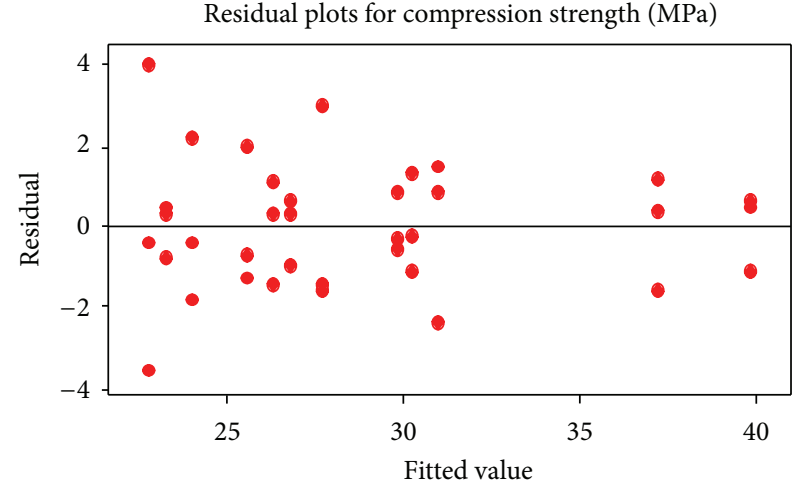

(b) Versus fits

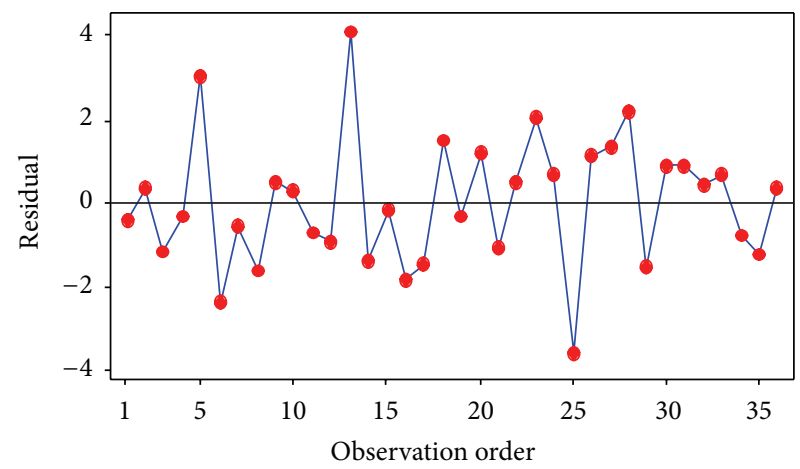

(d) Versus order

FIGURE 6: Regression analysis of $\sigma_{\mathrm{cp}}$ trial.

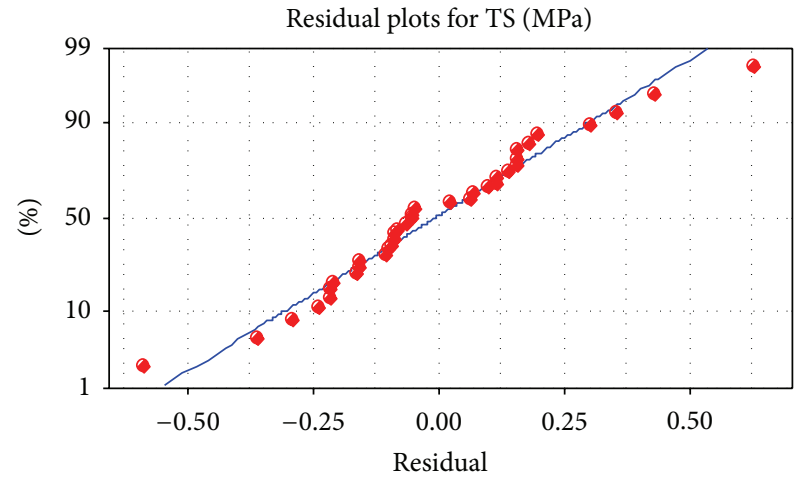

(a) Normal probability plot

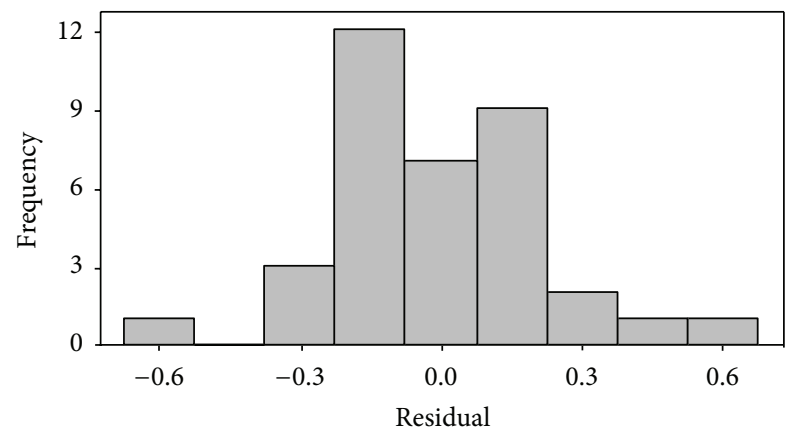

(c) Histogram

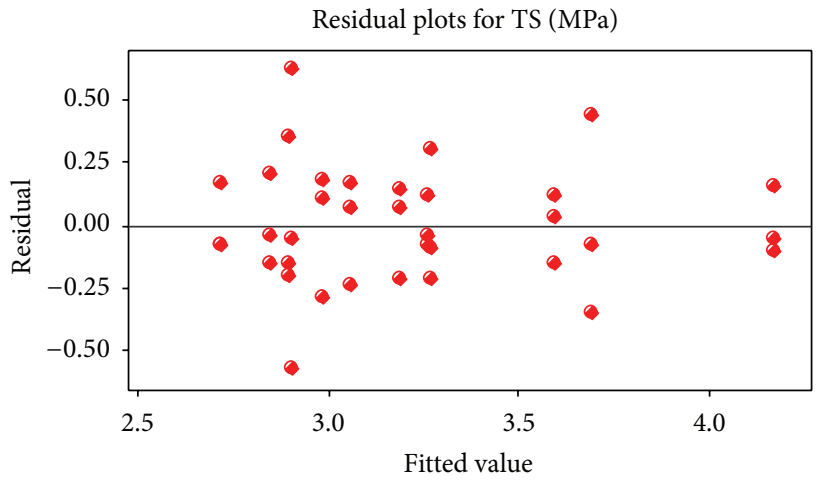

(b) Versus fits

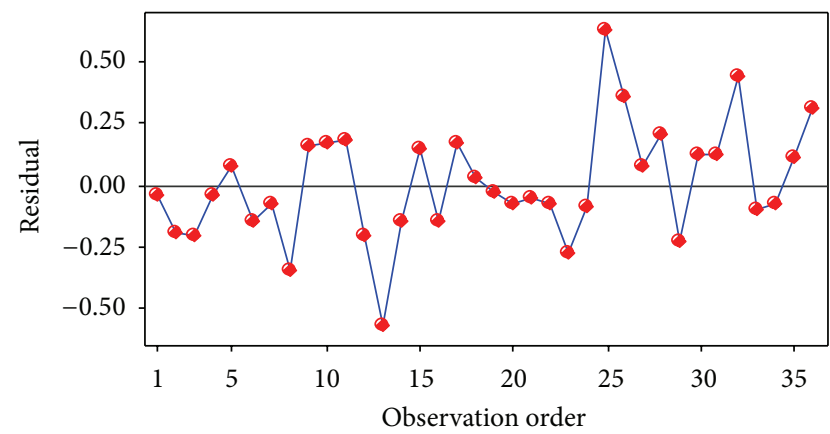

(d) Versus order

FIGURE 7: Regression analysis of $\sigma_{\text {tr }}$ trial. 
TABLE 2: Design of experiment generated by MINITAB.

\begin{tabular}{|c|c|c|c|c|c|c|c|c|}
\hline \multicolumn{9}{|c|}{ MINITAB_-Design table } \\
\hline StdOrder & RunOrder & PtType & Blocks & $\% \mathrm{CNT}$ & Age & $\sigma_{\mathrm{cp}}(\mathrm{MPa})$ & $\sigma_{\mathrm{tr}}(\mathrm{MPa})$ & $\mathrm{EMO}_{d}(\mathrm{GPa})$ \\
\hline 1 & 1 & 1 & 1 & 0.0 & 3 & 22.23 & 2.85 & 21,821 \\
\hline 2 & 2 & 1 & 1 & 0.0 & 7 & 26.60 & 2.69 & 21,759 \\
\hline 3 & 3 & 1 & 1 & 0.0 & 28 & 29.10 & 2.98 & 22,713 \\
\hline 4 & 4 & 1 & 1 & 0.2 & 3 & 23.57 & 2.80 & 22,238 \\
\hline 5 & 5 & 1 & 1 & 0.2 & 7 & 30.65 & 3.13 & 22,051 \\
\hline 6 & 6 & 1 & 1 & 0.2 & 28 & 28.54 & 3.45 & 22,904 \\
\hline 7 & 7 & 1 & 1 & 0.4 & 3 & 29.27 & 3.18 & 26,821 \\
\hline 8 & 8 & 1 & 1 & 0.4 & 7 & 35.58 & 3.34 & 26,809 \\
\hline 9 & 9 & 1 & 1 & 0.4 & 28 & 40.39 & 4.34 & 28,626 \\
\hline 10 & 10 & 1 & 1 & 0.6 & 3 & 23.46 & 2.88 & 20,989 \\
\hline 11 & 11 & 1 & 1 & 0.6 & 7 & 24.83 & 3.17 & 23,956 \\
\hline 12 & 12 & 1 & 1 & 0.6 & 28 & 25.81 & 3.06 & 25,685 \\
\hline 13 & 13 & 1 & 1 & 0.0 & 3 & 26.75 & 2.32 & 21,743 \\
\hline 14 & 14 & 1 & 1 & 0.0 & 7 & 24.87 & 2.74 & 22,046 \\
\hline 15 & 15 & 1 & 1 & 0.0 & 28 & 30.04 & 3.34 & 23,521 \\
\hline 16 & 16 & 1 & 1 & 0.2 & 3 & 22.11 & 2.69 & 21,470 \\
\hline 17 & 17 & 1 & 1 & 0.2 & 7 & 26.18 & 3.22 & 22,729 \\
\hline 18 & 18 & 1 & 1 & 0.2 & 28 & 32.45 & 3.63 & 22,611 \\
\hline 19 & 19 & 1 & 1 & 0.4 & 3 & 29.49 & 3.22 & 27,045 \\
\hline 20 & 20 & 1 & 1 & 0.4 & 7 & 38.39 & 3.61 & 27,274 \\
\hline 21 & 21 & 1 & 1 & 0.4 & 28 & 38.77 & 4.12 & 28,613 \\
\hline 22 & 22 & 1 & 1 & 0.6 & 3 & 23.68 & 2.64 & 22,377 \\
\hline 23 & 23 & 1 & 1 & 0.6 & 7 & 27.54 & 2.70 & 24,975 \\
\hline 24 & 24 & 1 & 1 & 0.6 & 28 & 27.36 & 3.18 & 25,011 \\
\hline 25 & 25 & 1 & 1 & 0.0 & 3 & 19.04 & 3.53 & 21,341 \\
\hline 26 & 26 & 1 & 1 & 0.0 & 7 & 27.35 & 3.25 & 21,612 \\
\hline 27 & 27 & 1 & 1 & 0.0 & 28 & 31.61 & 3.26 & 22,960 \\
\hline 28 & 28 & 1 & 1 & 0.2 & 3 & 26.15 & 3.05 & 22,008 \\
\hline 29 & 29 & 1 & 1 & 0.2 & 7 & 26.06 & 2.82 & 21,914 \\
\hline 30 & 30 & 1 & 1 & 0.2 & 28 & 31.81 & 3.72 & 21,883 \\
\hline 31 & 31 & 1 & 1 & 0.4 & 3 & 30.71 & 3.38 & 27,259 \\
\hline 32 & 32 & 1 & 1 & 0.4 & 7 & 37.59 & 4.13 & 28,040 \\
\hline 33 & 33 & 1 & 1 & 0.4 & 28 & 40.54 & 4.08 & 28,897 \\
\hline 34 & 34 & 1 & 1 & 0.6 & 3 & 22.41 & 2.63 & 23,460 \\
\hline 35 & 35 & 1 & 1 & 0.6 & 7 & 24.26 & 3.09 & 24,669 \\
\hline 36 & 36 & 1 & 1 & 0.6 & 28 & 27.05 & 3.58 & 25,152 \\
\hline
\end{tabular}

the inputs 13 and 25 of Table 2 reported from MINITAB as "Unusual Observations for Compression and tensile Tests." These values correspond to the samples CN0, tested at the age of 3 days with results of $\sigma_{\mathrm{cp}}$ and $\sigma_{\mathrm{tr}}$ far from the average. This may be due to an error in the reading process or the poor quality of the specimens.

Figures 8 and 9 show the variation of the average value of the compressive strength and tensile strength by diametrical compression, respectively, with the percentage of carbon nanotubes and the age of the samples of mortar.

It can be observed that the composite with $0.4 \%$ of nanotubes had the best performance at all ages with substantial increase of compressive strength and tensile strength, compared to reference sample CN0. The compressive strength had the highest gain at the age of 7 days in about $42 \%$, while the tensile strength reached its peak with an increase of approximately $31 \%$ at age of 28 days.

The insertion of carbon nanotubes in composites CN2 and CN6 did not affect significantly the result of the compressive strength, still being observed that the samples CN6 had had their values reduced at the ages of 7 days and 28 days.

However, it is noteworthy that all samples with carbon nanotubes had increases in the tensile strength at ages 7 days and 28 days. The CN2 sample reached a gain of $12.85 \%$ at the 
TABLE 3: Compressive strength.

\begin{tabular}{llccccc}
\hline Age & Parameters & CN0 & CN2 & CN4 & CN6 & Average \\
\hline \multirow{4}{*}{3 days } & Average $\sigma_{\text {cp }}(\mathrm{MPa})$ & 22,67 & 23,94 & 29,82 & 23,18 \\
& Standard deviation & 3,86470 & 2,04571 & 0,77571 & 0,67870 \\
& Variance & 14,93590 & 4,18493 & 0,60173 & 0,40630 \\
& \% gain/(reduction) & - & 5,60 & 31,53 & 2,25 & 25,54 \\
7 days & Average $\sigma_{\text {cp }}(\mathrm{MPa})$ & 26,27 & 27,63 & 37,19 & 1,75249 \\
& Standard deviation & 1,27186 & 2,61608 & 1,44777 & 3,07123 \\
& Variance & 1,61763 & 6,84390 & 2,09603 & $(2,77)$ \\
28 days & \% gain/(reduction) & - & 5,16 & 41,54 & 26,74 \\
& Average $\sigma_{\text {cp }}(\mathrm{MPa})$ & 30,25 & 30,93 & 39,90 & 0,16 \\
& Standard deviation & 1,26811 & 2,09724 & 0,98148 & 0,82018 \\
Average & Variance & 1,60810 & 4,39843 & 0,96330 & 0,67270 \\
\hline
\end{tabular}

TABLE 4: Tensile strength by diametric compression.

\begin{tabular}{|c|c|c|c|c|c|c|}
\hline Age & Parameters & CN0 & $\mathrm{CN} 2$ & $\mathrm{CN} 4$ & CN6 & Average \\
\hline \multirow{4}{*}{3 days } & Average $\sigma_{\mathrm{tr}}(\mathrm{MPa})$ & 2,900 & 2,847 & 3,260 & 2,717 & \multirow{4}{*}{2,931} \\
\hline & Standard deviation & 0,60655 & 0,18448 & 0,10583 & 0,14154 & \\
\hline & Variance & 0,36790 & 0,03403 & 0,01120 & 0,02003 & \\
\hline & $\%$ gain/(reduction) & - & $(1,80)$ & 12,41 & $(6,20)$ & \\
\hline \multirow{4}{*}{7 days } & Average $\sigma_{\mathrm{tr}}(\mathrm{MPa})$ & 2,893 & 3,057 & 3,693 & 2,987 & \multirow{4}{*}{3,158} \\
\hline & Standard deviation & 0,30989 & 0,20984 & 0,40154 & 0,25146 & \\
\hline & Variance & 0,09603 & 0,4403 & 0,16123 & 0,06323 & \\
\hline & $\%$ gain/(reduction) & - & 5,65 & 27,68 & 3,46 & \\
\hline \multirow{4}{*}{28 days } & Average $\sigma_{\mathrm{tr}}(\mathrm{MPa})$ & 3,193 & 3,600 & 4,180 & 3,273 & \multirow{4}{*}{3,562} \\
\hline & Standard deviation & 0,18903 & 0,13748 & 0,14000 & 0,27227 & \\
\hline & Variance & 0,03573 & 0,01890 & 0,01960 & 0,07413 & \\
\hline & $\%$ gain/(reduction) & - & 12,85 & 31,03 & 2,51 & \\
\hline Average & & 2,966 & 3,168 & 3,711 & 2,992 & \\
\hline
\end{tabular}

age of 28 days in relation to the reference sample CN0. This result corroborates the good performance of the nanotubes in improving the tensile strength, acting in a significant way on the weak point of the concrete which is its tensile strength [16].

The fact that the sample CN4 has had better performance may indicate that there is a range considered "optimal" to the insertion of nanotubes into arrays of cement, and this band should be close to the values quoted. It was still noticed that, out of that band, there is no significant gain and even loss of resistance can occur.

The increase obtained in the compressive strength is also related to the dispersion of carbon nanotubes in the array. When the dispersion is well performed, the nanotubes are diluted in the cement paste homogenously by making interconnections with the calcium silicate, hydrated with the grains of the mixture with no occurrence of punctual agglomeration. This leads to a denser matrix which contributes to obtaining a new tougher material [17].

The graphics in Figures 8 and 9 also provide a more general statistical view of what goes on with the experiment due to the interference of the variables in the process. The variation of the average values of compressive strength and tensile strength can be seen, with the combination of each level of a variable with the levels of the other variables. The compression test shows that there is only interaction between the curves representing the samples with the percentage of carbon nanotubes of $0.0 \%$ and $0.6 \%$ in the ages between 3 days and 7 days when the average value of the $\sigma_{\mathrm{cp}}$ of the composites reaches a level around $24 \mathrm{MPa}$. On the other hand, the tensile test depicts an interaction between the curves $\mathrm{CN} 0, \mathrm{CN} 2$, and CN6 in the ages between 3 days and 7 days when the average tensile strength of the mixture reaches a level of around $2.90 \mathrm{MPa}$.

Figures 10 and 11 show a three-dimensional view of the result of the test performed with cement samples with and without carbon nanotube for comparative evaluation of compression and traction resistances. This chart is often used to identify the conditions for parameter optimization in conducting an experiment.

It can be seen clearly from the graphic of Figure 10 that the peak of $\sigma_{\mathrm{tr}}$ occurs for the composite $\mathrm{CN} 4$ at the age of 


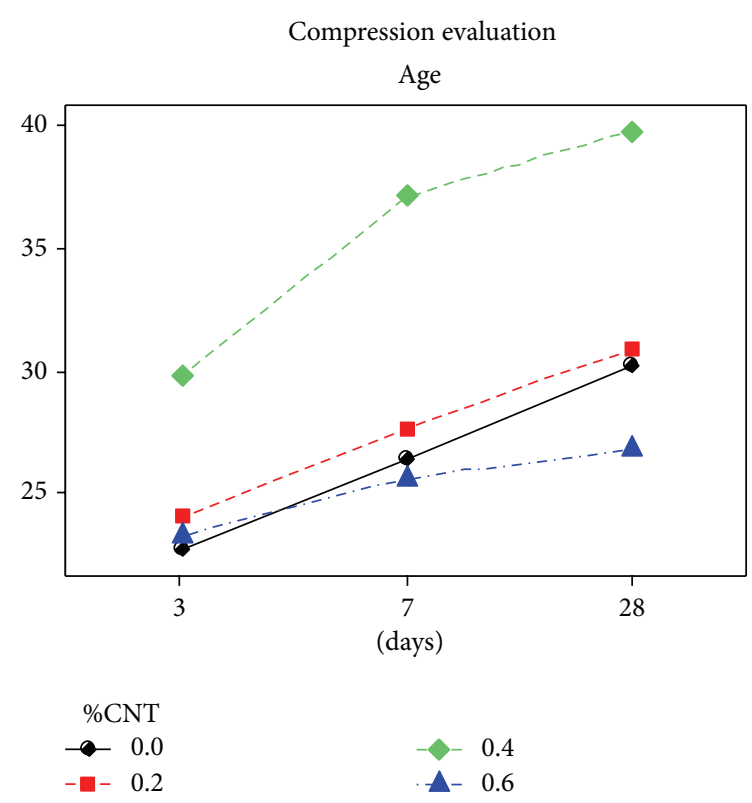

(a)

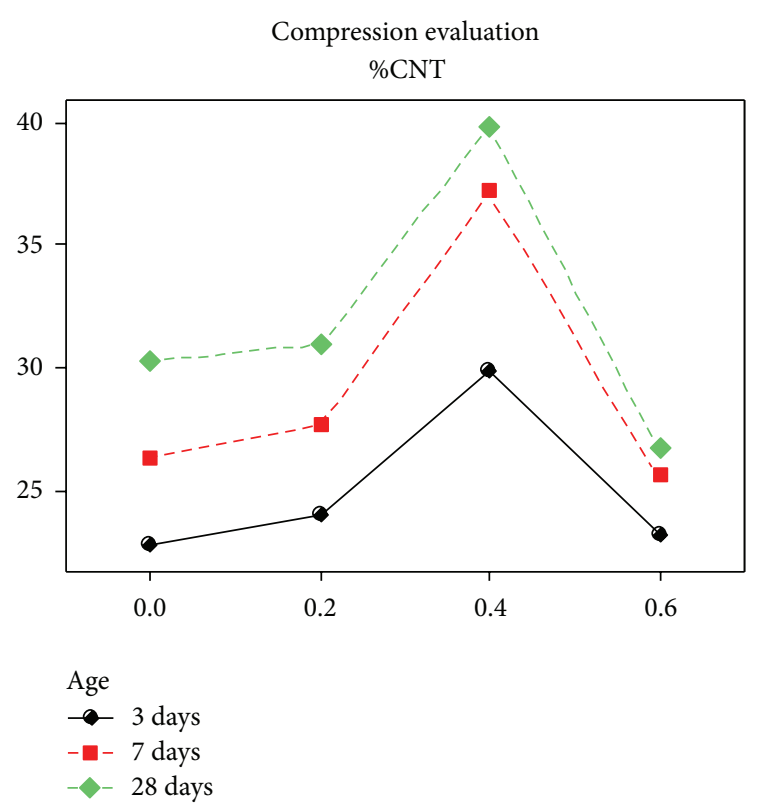

(b)

FIGURE 8: Average variation of the compression strength.

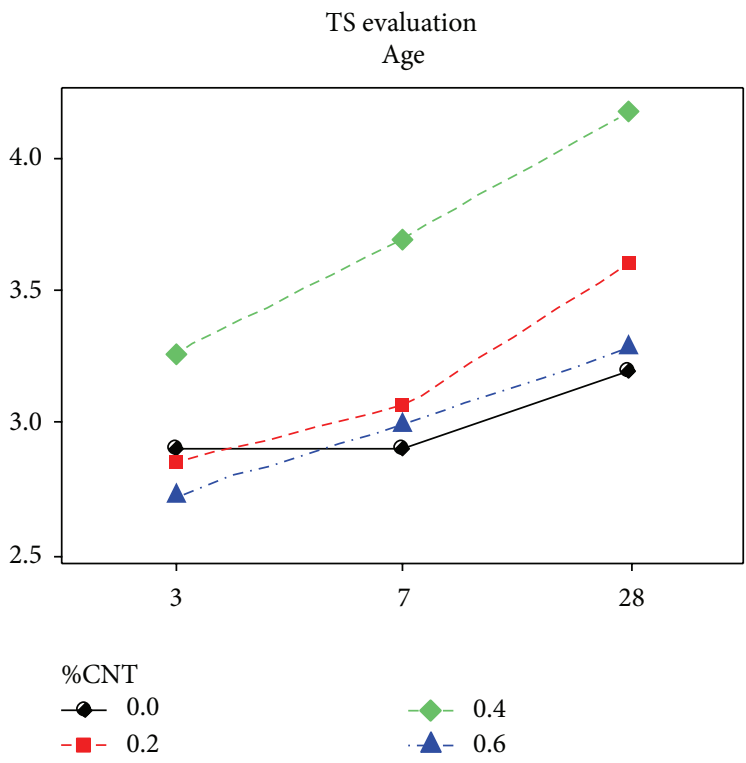

(a)

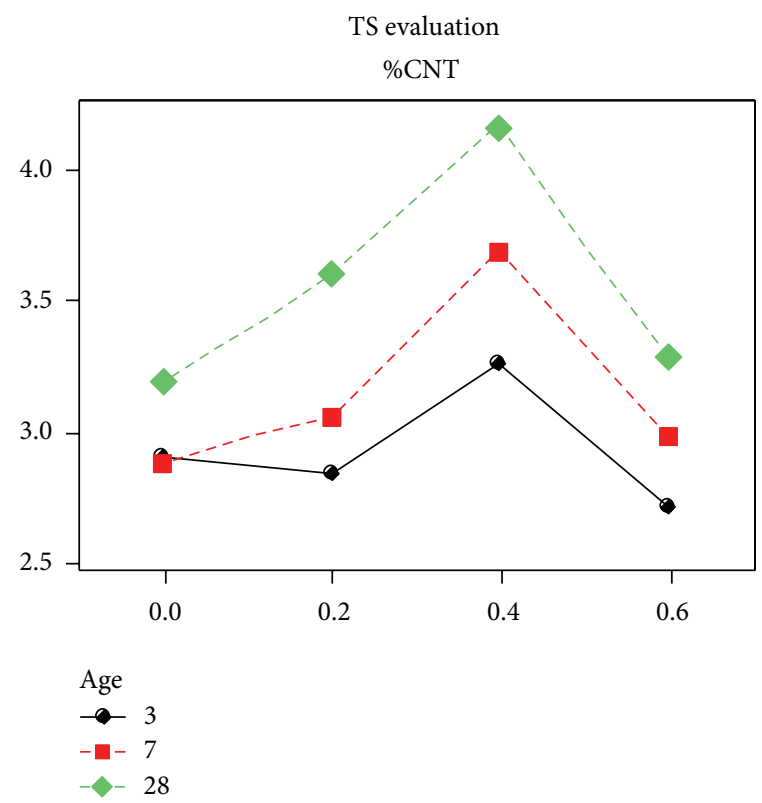

(b)

FIGURE 9: Average variation of the tensile strength.

28 days when it reaches the value of $39.90 \mathrm{MPa}$, and from the graphic of Figure 11, the peak of $\sigma_{\mathrm{tr}}$ occurs, for the same composite $\mathrm{CN} 4$ with the age of 28 days when it reaches the value of $4.18 \mathrm{MPa}$.

Figure 12, "the main effects plot," shows the evolution of the averages of $\sigma_{\mathrm{cp}}$ and $\sigma_{\mathrm{tr}}$ with each value of each variable, combining the effect of the other variables as if they were independent.

In Figure 12(a), it can be seen, for example, that the average of $\sigma_{\mathrm{cp}}$ is around $25 \mathrm{MPa}$ in the age of 3 days of $29 \mathrm{MPa}$ at the age of 7 days and $32 \mathrm{MPa}$ at the age of 28 days. From the viewpoint of the variable (NTC\%), the average value of 


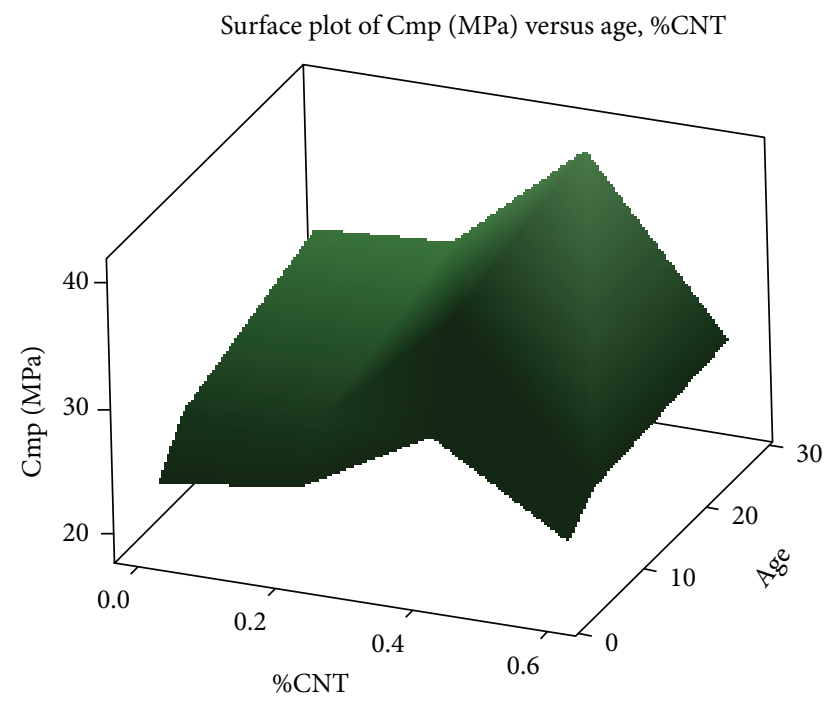

Figure 10: Response surface in three dimensions to $\sigma_{\mathrm{cp}}$.

Surface plot of TS (MPa) versus \%CNT, age

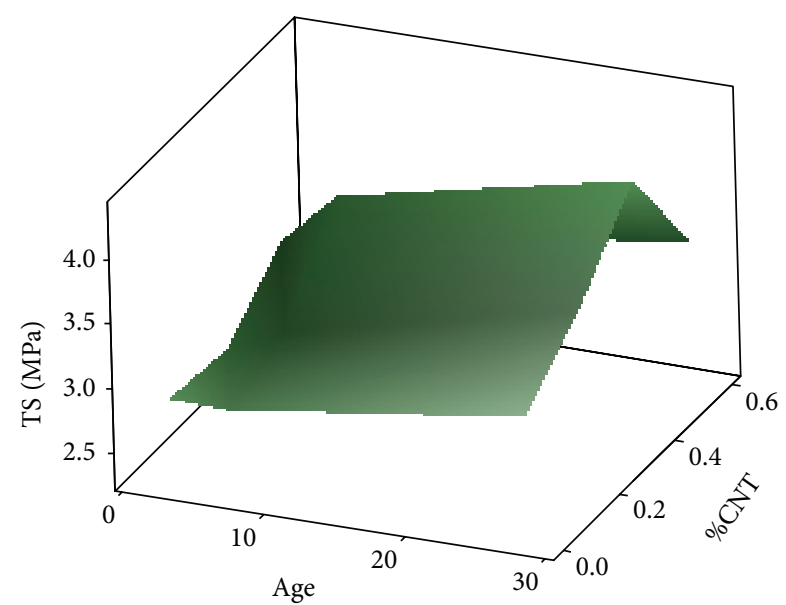

FIGURE 11: Response surface in three dimensions to $\sigma_{\mathrm{tr}}$.

the $\sigma_{\mathrm{cp}}$ is around $26.5 \mathrm{MPa}$ for the CN0 composite, evolving to $27.5 \mathrm{MPa}$ for $\mathrm{CN} 2$, reaching $35.5 \mathrm{MPa}$ for mixing $\mathrm{CN} 4$ and backing off for $25 \mathrm{MPa}$ to the samples of $0.6 \%$. of nanotubes.

Figure 12(b) shows the evolution of the average resistance to traction of the samples. It is noted that the average value of $\sigma_{\mathrm{tr}}$, is around $2.93 \mathrm{MPa}$ at the age of 3 days increasing for $3.15 \mathrm{MPa}$ at 7 days and reaching $3.56 \mathrm{MPa}$ at 28 days of age. From the point of view of the variable, percentage of nanotubes, the average of $\sigma_{\mathrm{tr}}$ is $3.0 \mathrm{MPa}$ for $\mathrm{CN} 0$, passing to 3.17 MPa for CN2, peaking 3.71 MPa for the CN4 mixing, and falling to 3.0 $\mathrm{MPa}$ with the $\mathrm{CN} 6$ composite.

\subsection{Evaluation of the Dynamic Modulus of Elasticity $\left(M O E_{d}\right)$.} Table 5 summarizes the statistical parameters representing the result of ultrasound test conducted for obtaining the dynamic modulus of elasticity of the samples.
With the values of $\mathrm{MOE}_{d}$ inserted in Table 2, the MINITAB program, using the technique of regression analysis, generated the statistical profile model to the nondestructive test represented by the graphics in Figure 13.

It is possible to see from Figure 13(a), that the values of $\mathrm{MOE}_{d}$ are distributed on concentrated form, almost entirely along the straight line, which leads us to conclude that the model performed by the test has the profile of a normal distribution. This fact is ratified by the histogram (Figure 13(c)); it is configured with a symmetry bell-shaped, which is evenly distributed around zero, showing that the assumption of normality is likely to be true.

Figures 13(b) and 13(d) depict an experiment with consistent methodology since the residues are randomly distributed around zero on a band within $\pm 5 \%$, meaning that there is no deviation in the process. The divergences found on these graphs are the values corresponding to the inputs 10 and 34 of Table 2 reported from MINITAB as "Unusual Observations for $\mathrm{Emo}_{d}$ " These values correspond to the two samples of CN6 tested in the age of 3 days with results of $\mathrm{MOE}_{d}$ far from the average. This may be due to an error in the reading process or the poor quality of the specimens.

\subsection{Evaluation of the Resistance of Materials to Bending} Stresses. The results reported by the INCOTECNI press, during the bending test of samples CN0 and CN4, are shown in Table 6, and the graphic corresponding to the curves of flexion in the form of load versus deformation is displayed in Figure 14.

The curves of flexion, obtained from the test, show that the composite CN4 resulted in the best performance with the breaking point of $2.99 \mathrm{kN}$ exceeding $15 \%$ of the breaking load supported by the mixing without nanotubes (CN0). This result corroborates, this important characteristic of the carbon nanotubes that is, causing significant improvement occurs in the well-known weakness of concrete which is their low resistance to bending.

Figure 14 also shows that from the beginning of application of the load to point of rupture, the sample CN4 withstood a deformation of $0.90 \mathrm{~mm}$, whereas with the sample CN0, the deformation was $0.81 \mathrm{~mm}$, indicating that the insertion of nanotube made the composite more malleable, that is, with greater deformation capacity, and so can withstand more loading.

As a reference, we mention that $\mathrm{Li}$ et al. [18] had performed the test of flexion in prismatic samples with dimensions of $4 \times 4 \times 16 \mathrm{~cm}$ achieving a $25 \%$ increase in the flexural strength for mortars with content of $0.50 \%$ of carbon nanotube treated. Batiston [19], however, achieved lower results with the largest value of around 5\% for the same test and samples of same dimensions as those used by $\mathrm{Li}$ et al. Batiston justifies the difference in the result due to the form factor of carbon nanotubes used, a fact that may have influenced the test results.

In general, there are factors that may contribute to the differentiation in the results, for example, the type of additive used, the form factor of the CNT, the methodology used in the manufacture of samples, the curing process of the material, 


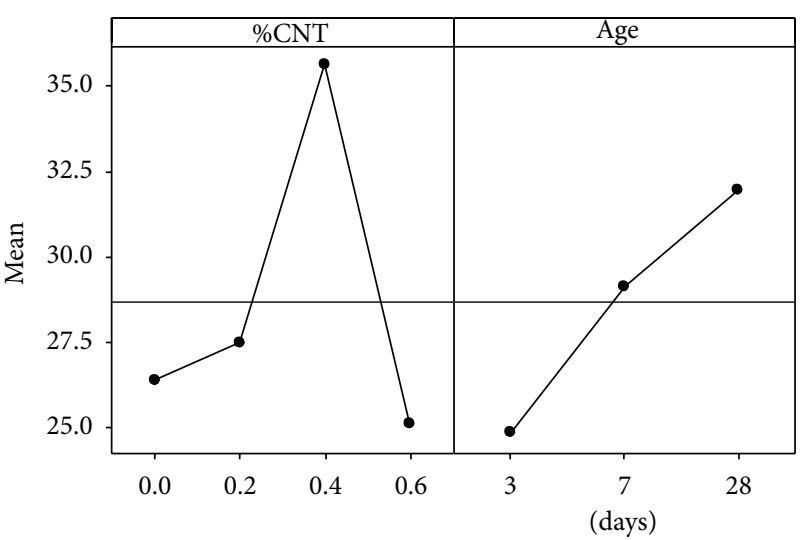

(a) Compression evaluation

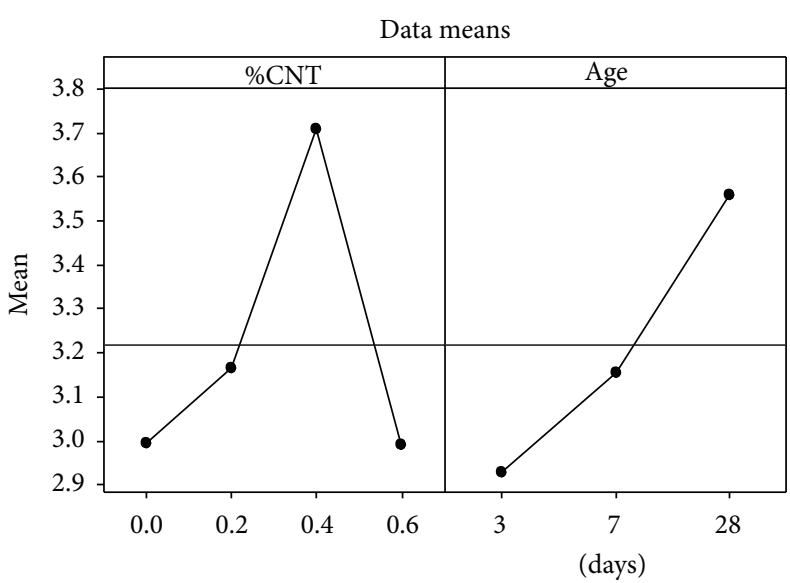

(b) Main effects plot for TS (MPa)

FIGURE 12: Main effects plot for compression and tensile strengths.

TABle 5: Dynamic modulus of elasticity.

\begin{tabular}{|c|c|c|c|c|c|c|}
\hline Age & Parameters & CNO & $\mathrm{CN} 2$ & $\mathrm{CN} 4$ & CN6 & Average \\
\hline \multirow{4}{*}{3 days } & Average $\mathrm{EMO}_{d}(\mathrm{GPa})$ & 21,635 & 21,905 & 27,042 & 22,275 & \multirow{4}{*}{23,214} \\
\hline & Standard deviation & 0,25758 & 0,39416 & 0,21902 & 1,23863 & \\
\hline & Variance & 0,06635 & 0,15536 & 0,04797 & 1,53421 & \\
\hline & $\%$ gain/(reduction) & - & 1,24 & 24,99 & 2,96 & \\
\hline \multirow{4}{*}{7 days } & Average $\mathrm{EMO}_{d}(\mathrm{GPa})$ & 21,806 & 22,231 & 27,374 & 24,533 & \multirow{4}{*}{23,986} \\
\hline & Standard deviation & 0,22073 & 0,43640 & 0,62160 & 0,52287 & \\
\hline & Variance & 0,04872 & 0,19045 & 0,38639 & 0,27339 & \\
\hline & $\%$ gain/(reduction) & - & 1,95 & 25,53 & 12,50 & \\
\hline \multirow{4}{*}{28 days } & Average $\mathrm{EMO}_{d}(\mathrm{GPa})$ & 23,065 & 22,466 & 28,712 & 25,283 & \multirow{4}{*}{24,882} \\
\hline & Standard deviation & 0,41404 & 0,52572 & 0,16035 & 0,35549 & \\
\hline & Variance & 0,17143 & 0,27638 & 0,02571 & 0,12637 & \\
\hline & $\%$ gain/(reduction) & - & $(2,59)$ & 24,48 & 9,62 & \\
\hline Average & & 22,168 & 22,201 & 27,709 & 24,030 & \\
\hline
\end{tabular}

and so on. But, in all cases reported, the insertion of CNT in cementitious composites resulted in improvement in their mechanical properties [20].

3.4. Assessment of the Microstructure of the Samples. The porosity tests and evaluation by SEM were performed for the different blends, at the age of 28 days. The results obtained on the percentage of pores and the apparent and relative densities of the samples are shown in Table 7.

The apparent density considers the effect of the pores and, hence, the amount of water contained in the sample volume, while the relative density excludes the influence of the water on the measuring process and is therefore higher than the apparent density [21].

For a comparative view of the magnitudes of the average values obtained from test porosity, Figures 15 and 16 show, respectively, the variation of the percentage of pores and of the densities with addition of different amounts of carbon nanotubes in the mortar samples.
The values of the relative density and apparent density for the four samples were very close however, the sample CN4 presented the largest value, indicating a more dense structure caused probably by the filling of the pores and by the better interconnection between the grains of the mix due to the presence of the nanotube percentage that showed the best results.

In evaluating the porosity of the samples, the CN4 blend also showed the better performance with a reduction of approximately $15 \%$ of pores compared to the reference mixture CN0. This result leads us to understand that the composite with $0.4 \%$ of carbon nanotubes showed a denser structure not only by filling the pores but also by the formation of more products from hydration, producing pores with smaller diameters. It is also observed that the samples CN2 showed no significant improvement in their microstructure and the mixture CN6 even worsened with the insertion of carbon nanotubes [22].

The decrease in the percentage of pores and the increase in the density of the mixture with insertion of nanotubes are a 


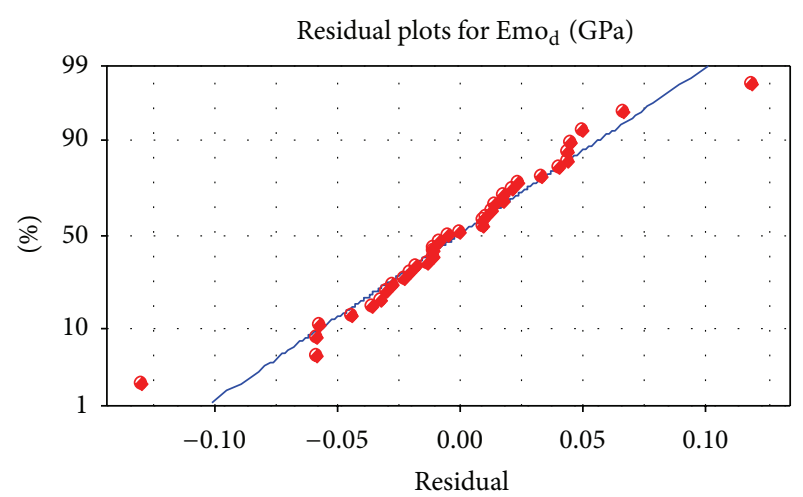

(a) Normal probability plot

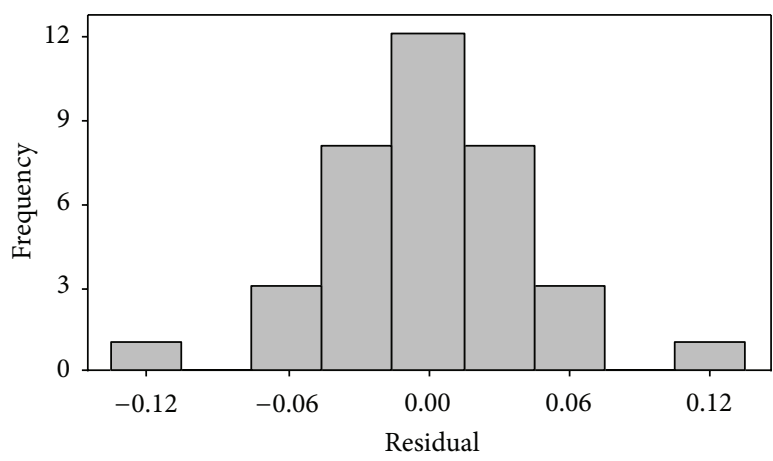

(c) Histogram

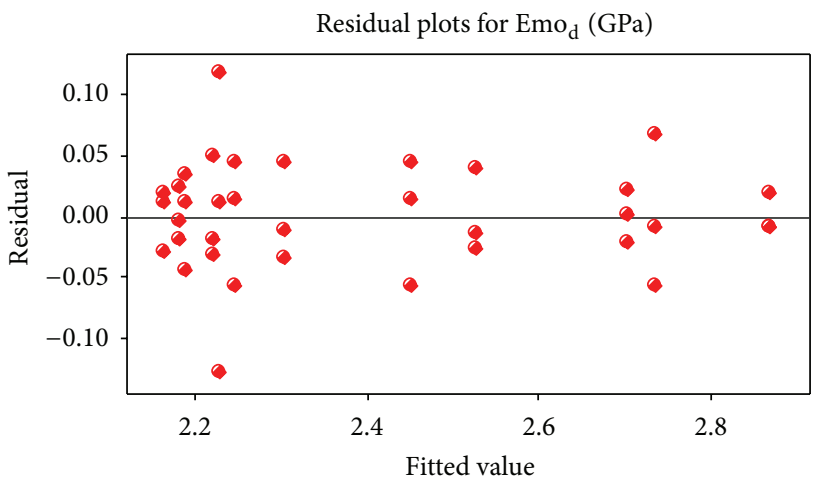

(b) Versus fits

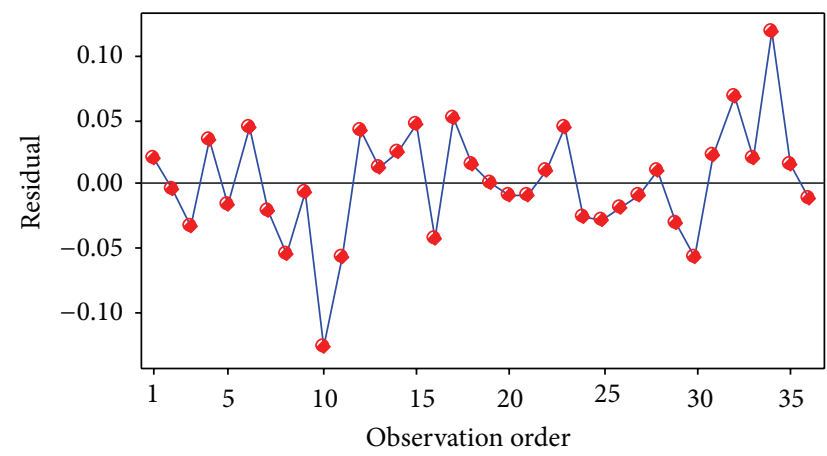

(d) Versus order

FIGURE 13: Regression analysis of the $\mathrm{MOE}_{d}$ search.

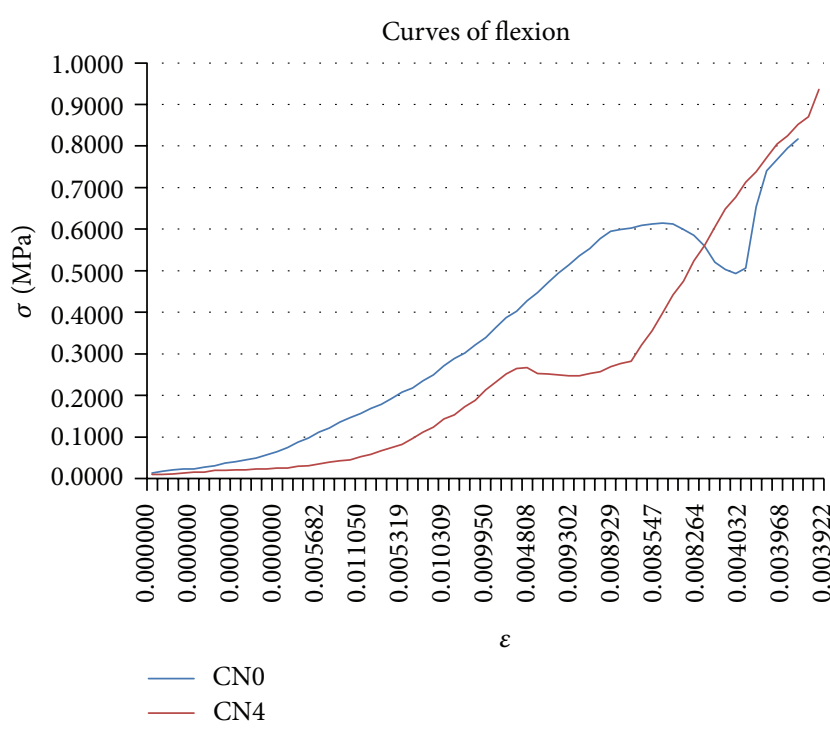

FIgURE 14: Flexural curves of the samples of CN4 and CN0, of dimensions $4 \times 4 \times 16 \mathrm{~cm}$ at age of 28 days $\sigma(\mathrm{MPa})=F / S, \varepsilon=\left(\right.$ def $_{2}-$ $\left.\operatorname{def}_{1}\right) / \operatorname{def}_{1}$.

positive factor for the durability of concrete structures, since, with such a microstructure, the movement of aggressive agents within the material becomes more difficult.

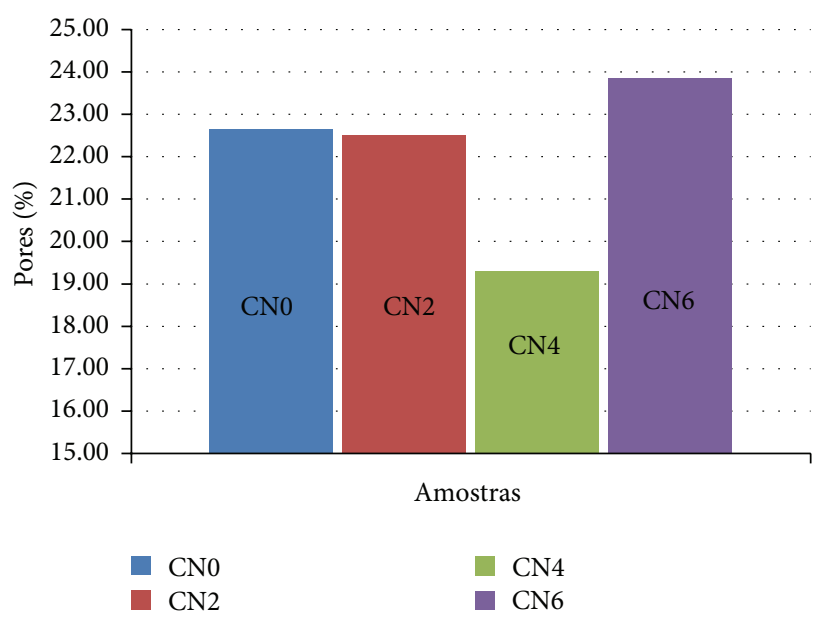

FIGURE 15: Variation of the mean values of the percentage of pores of the samples.

Using the SEM technique, it was possible to visualize, through images, the structure of the samples, the material present, and even certain details of byproducts formed by the hydration of cement. The SEM images obtained for samples of mortar CN0, CN2, CN4, and CN6 increased several times as indicated in each set of images which are shown in Figures 17 and 18. 
TABLE 6: Results of flexural test.

\begin{tabular}{|c|c|c|c|}
\hline \multicolumn{4}{|c|}{ Measures of the flexural test } \\
\hline \multicolumn{2}{|c|}{ CN0 } & \multicolumn{2}{|c|}{$\mathrm{CN} 4$} \\
\hline Strength & Def. & Strength & Def. \\
\hline 0,0440 & 2,83 & 0,0314 & 1,66 \\
\hline 0,0566 & 2,84 & 0,0314 & 1,66 \\
\hline 0,0691 & 2,85 & 0,0377 & 1,66 \\
\hline 0,0754 & 2,85 & 0,0440 & 1,67 \\
\hline 0,0754 & 2,86 & 0,0503 & 1,67 \\
\hline 0,0880 & 2,87 & 0,0503 & 1,67 \\
\hline 0,1006 & 2,88 & 0,0628 & 1,68 \\
\hline 0,1194 & 2,89 & 0,0628 & 1,69 \\
\hline 0,1320 & 2,90 & 0,0691 & 1,69 \\
\hline 0,1445 & 2,91 & 0,0691 & 1,70 \\
\hline 0,1571 & 2,92 & 0,0754 & 1,71 \\
\hline 0,1823 & 2,93 & 0,0754 & 1,72 \\
\hline 0,2074 & 2,94 & 0,0817 & 1,72 \\
\hline 0,2388 & 2,95 & 0,0817 & 1,74 \\
\hline 0,2828 & 2,97 & 0,0943 & 1,75 \\
\hline 0,3142 & 2,98 & 0,1006 & 1,76 \\
\hline 0,3582 & 2,99 & 0,1131 & 1,77 \\
\hline 0,3897 & 3,00 & 0,1257 & 1,78 \\
\hline 0,4336 & 3,02 & 0,1383 & 1,80 \\
\hline 0,4714 & 3,03 & 0,1445 & 1,81 \\
\hline 0,5028 & 3,04 & 0,1697 & 1,83 \\
\hline 0,5405 & 3,06 & 0,1885 & 1,84 \\
\hline 0,5719 & 3,07 & 0,2137 & 1,86 \\
\hline 0,6159 & 3,08 & 0,2388 & 1,88 \\
\hline 0,6662 & 3,10 & 0,2640 & 1,89 \\
\hline 0,6976 & 3,11 & 0,3080 & 1,91 \\
\hline 0,7542 & 3,13 & 0,3582 & 1,93 \\
\hline 0,7982 & 3,14 & 0,3959 & 1,94 \\
\hline 0,8673 & 3,16 & 0,4588 & 1,96 \\
\hline 0,9239 & 3,17 & 0,4902 & 1,98 \\
\hline 0,9679 & 3,18 & 0,5531 & 1,99 \\
\hline 1,0307 & 3,20 & 0,6033 & 2,01 \\
\hline 1,0873 & 3,21 & 0,6850 & 2,03 \\
\hline 1,1627 & 3,22 & 0,7416 & 2,04 \\
\hline 1,2381 & 3,24 & 0,8045 & 2,06 \\
\hline 1,2884 & 3,25 & 0,8484 & 2,08 \\
\hline 1,3701 & 3,26 & 0,8547 & 2,09 \\
\hline 1,4329 & 3,27 & 0,8107 & 2,11 \\
\hline 1,5083 & 3,29 & 0,8045 & 2,13 \\
\hline 1,5838 & 3,30 & 0,7982 & 2,15 \\
\hline 1,6466 & 3,31 & 0,7919 & 2,17 \\
\hline 1,7157 & 3,32 & 0,7919 & 2,19 \\
\hline 1,7723 & 3,33 & 0,8107 & 2,22 \\
\hline 1,8477 & 3,34 & 0,8233 & 2,24 \\
\hline 1,9043 & 3,35 & 0,8610 & 2,26 \\
\hline 1,9169 & 3,36 & 0,8862 & 2,29 \\
\hline 1,9294 & 3,37 & 0,9050 & 2,31 \\
\hline
\end{tabular}

TABLE 6: Continued.

\begin{tabular}{|c|c|c|c|}
\hline \multicolumn{4}{|c|}{ Measures of the flexural test } \\
\hline \multicolumn{2}{|c|}{ CNO } & \multicolumn{2}{|c|}{$\mathrm{CN} 4$} \\
\hline Strength & Def. & Strength & Def. \\
\hline 1,9483 & 3,38 & 1,0307 & 2,34 \\
\hline 1,9609 & 3,40 & 1,1375 & 2,36 \\
\hline 1,9671 & 3,41 & 1,2758 & 2,38 \\
\hline 1,9609 & 3,42 & 1,4141 & 2,40 \\
\hline 1,9169 & 3,44 & 1,5209 & 2,42 \\
\hline 1,8729 & 3,45 & 1,6780 & 2,44 \\
\hline 1,7912 & 3,47 & 1,7912 & 2,45 \\
\hline 1,6655 & 3,49 & 1,9357 & 2,47 \\
\hline 1,6089 & 3,51 & 2,0740 & 2,48 \\
\hline 1,5775 & 3,54 & 2,1682 & 2,49 \\
\hline 1,6215 & 3,56 & 2,2814 & 2,50 \\
\hline 2,0928 & 3,58 & 2,3631 & 2,51 \\
\hline 2,3694 & 3,60 & 2,4699 & 2,52 \\
\hline 2,4573 & 3,61 & 2,5768 & 2,53 \\
\hline 2,5453 & 3,63 & 2,6396 & 2,54 \\
\hline \multirow[t]{3}{*}{2,6145} & 3,64 & 2,7276 & 2,55 \\
\hline & & 2,7842 & 2,55 \\
\hline & & 2,9959 & 2,56 \\
\hline
\end{tabular}

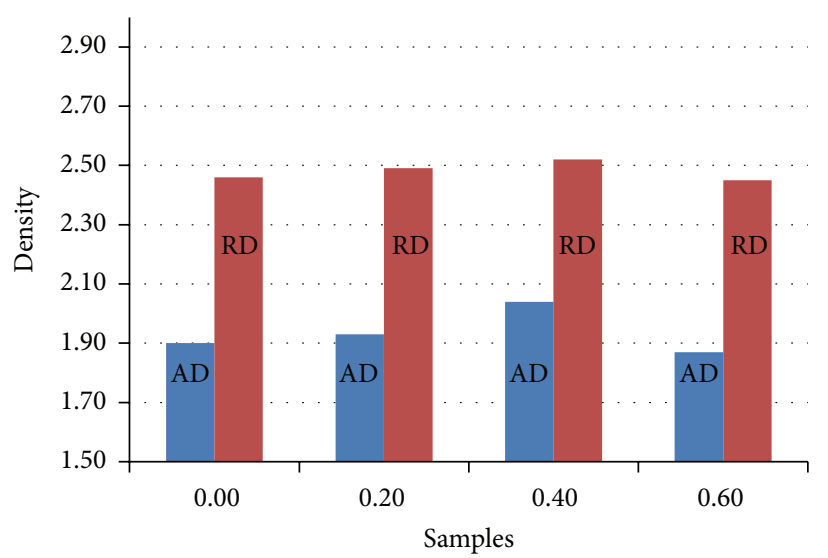

(\%) CNT

- Appar dens

Relat dens

FIGURE 16: Variation of the mean values of the densities of the samples.

The images for the sample CN0 confer with the theory as reported in the literature regarding the formation of acicular crystals single or in clusters which represent one of the products of the cement hydration: the ettringite. Beyond, it is possible to note the formation of some plates, which indicate the presence of calcium hydroxide.

It may be noted in the $\mathrm{CN} 2$ blend that the incorporation of nanotubes in the array has changed its morphology. By comparing the images between $\mathrm{CN} 2$ and $\mathrm{CN} 0$, magnified 10,000 times, for example, it is observed that $\mathrm{CN} 2$ contains acicular crystals smaller than those formed in the sample without nanotubes. The presence of carbon nanotubes in CN2 
TABLE 7: Porosity test results.

\begin{tabular}{|c|c|c|c|c|c|c|}
\hline \multicolumn{7}{|c|}{ Test of porosity } \\
\hline \multirow{2}{*}{ Samples } & \multicolumn{3}{|c|}{ Measurements } & \multicolumn{3}{|c|}{ Results } \\
\hline & Hydro weight & Saturat weight & Dry weight & Appar Dens & Relat Dens & Porosity \\
\hline CN0-S1 & 63,06 & 132,76 & 118,20 & 1,87 & 2,44 & 23,10 \\
\hline CN0-S2 & 65,34 & 140,49 & 125,98 & 1,93 & 2,48 & 22,20 \\
\hline Average & 64,20 & 136,63 & 122,09 & 1,90 & 2,46 & 22,65 \\
\hline CN2-S1 & 55,96 & 120,02 & 107,53 & 1,92 & 2,47 & 22,30 \\
\hline $\mathrm{CN} 2-\mathrm{S} 2$ & 85,73 & 185,44 & 165,96 & 1,94 & 2,51 & 22,70 \\
\hline Average & 70,85 & 152,73 & 136,75 & 1,93 & 2,49 & 22,50 \\
\hline CN4-S1 & 31,88 & 71,93 & 65,94 & 2,07 & 2,55 & 18,80 \\
\hline $\mathrm{CN} 4-\mathrm{S} 2$ & 60,12 & 132,41 & 120,52 & 2,00 & 2,50 & 19,80 \\
\hline Average & 46,00 & 102,17 & 93,23 & 2,04 & 2,52 & 19,30 \\
\hline CN6-S1 & 39,64 & 83,42 & 74,15 & 1,87 & 2,44 & 23,40 \\
\hline CN6-S1 & 60,53 & 127,71 & 113,02 & 1,87 & 2,47 & 24,30 \\
\hline Average & 50,09 & 105,57 & 93,59 & 1,87 & 2,45 & 23,85 \\
\hline
\end{tabular}

is also evident in the amplifications of 20,000 and 100,000 times.

In the images of the blend $\mathrm{CN} 4$, one can identify a greater concentration of carbon nanotubes arranged as web interlacing the compounds of hydrated cement. Another important difference between the samples is more homogeneous hydration observed in the $\mathrm{CN} 4$ compound, taking into account that this blend is formed by several acicular crystals evenly distributed, whereas in the sample without nanotubes these crystals are found in random points.

The sample CN6 apparently also showed morphology with better hydration than the reference sample CN0, since, as shown in the images, the acicular crystals are better dispersed in the matrix of the CN6. The presence of carbon nanotubes also provided a better connection of the cement clinker compared to the reference sample.

\section{Conclusions and Final Remarks}

Traditional materials in the construction industry, such as concrete, steel, asphalt coatings, and glass are used in large scale and produced in large quantities. To give just one example, the cementitious materials exist for over 2000 years, and currently more than two tons of concrete per person on average is used annually worldwide. Historically, the evaluation of the properties of these materials has only been possible in a macroscale.

The understanding of the nanoscale behavior of the cement matrix and its interaction with other components used in the built environment can provide a powerful approach to develop superior concrete with better properties and more effective control of the degradation process.

Carbon nanotubes, when incorporated into cementitious materials, present a remarkable characteristic, producing the best results with low levels of adding and behavior of Gaussian distribution that is, it identifies a range considered "optimal" for insertion of nanotubes, and out of this range, the properties of the composites have worse results.

In the experiment reported in this study, we found that the mixture of $0.4 \%$ of carbon nanotubes $(\mathrm{CN} 4)$ was the mortar that showed the best performance in relation to the reference sample, achieving an increase of approximately $40 \%$ in compressive strength, $30 \%$ in tensile strength, $15 \%$ in flexural strength, about $25 \%$ in the dynamic modulus of elasticity, and a higher rate of structural compaction. The composites with addition of $0.2 \%$ and $0.6 \%$ of CNT did not show significant results for these same characteristics.

Initially, a better performance for the tensile strength was expected, since nanotubes have good performance for this characteristic. Although the samples have shown significant gains on tensile strength, were found better results for the compressive strength of the materials with the addition of the carbon nanotubes were found.

The mechanical properties investigated are the most used in the field of cement based materials and serve as a measure of quality of mortars or concretes. The images of SEM and porosity tests were performed in order to obtain additional information about the microstructure of the new composites with nanotubes.

It is noteworthy that this experiment had a character purely of exploration comparative where the characteristics of the composites with nanotubes were compared with the equivalent characteristics of the pure mortar. Different results could be obtained for the same phenomena investigated if we changed, for example, the properties of materials such as nanotube type, the type of additives and granulometry of sand. But we believe that the results, in qualitative terms, will be the same.

The results derived from this research and from other studies in the literature leave no doubt of the benefits received by inserting carbon nanotubes in cementitious products. Besides the increments obtained on microstructure and mechanical properties of the composites, the use of 

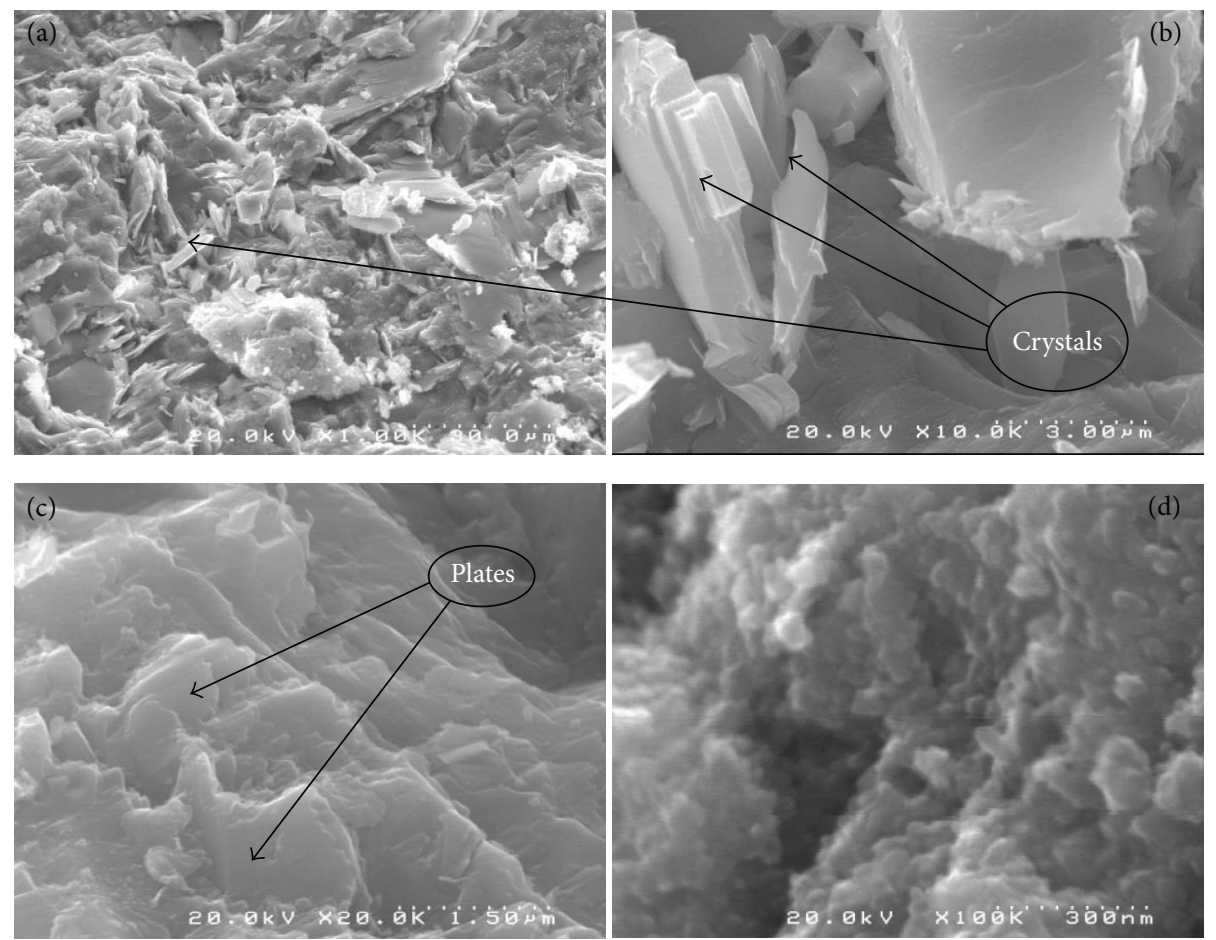

CN0 (1000/10.000/20.000/100.000 times)
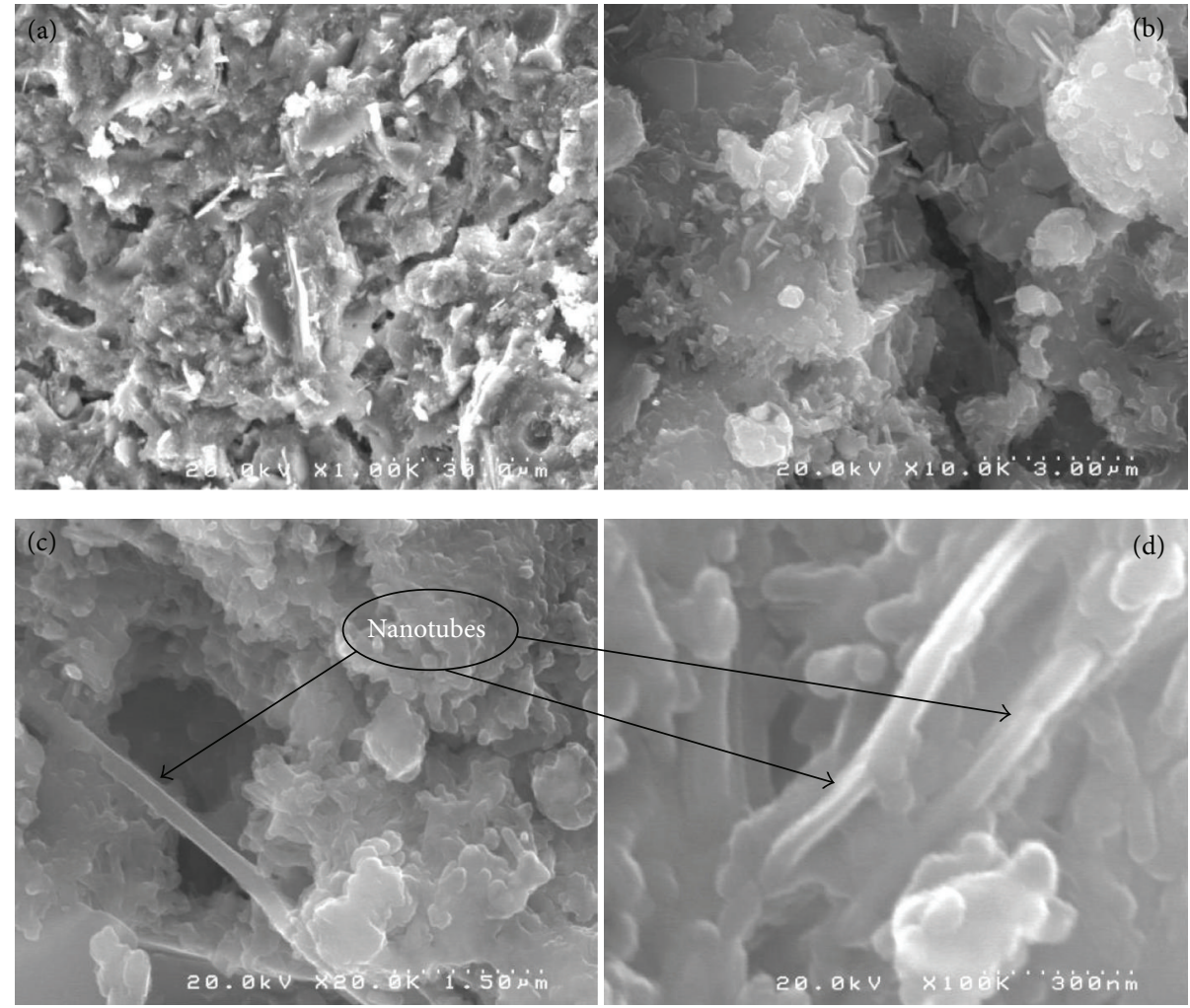

CN2 (1000/10.000/20.000/100.000 times)

FIGURE 17: SEM images of samples CN0 and CN2. 

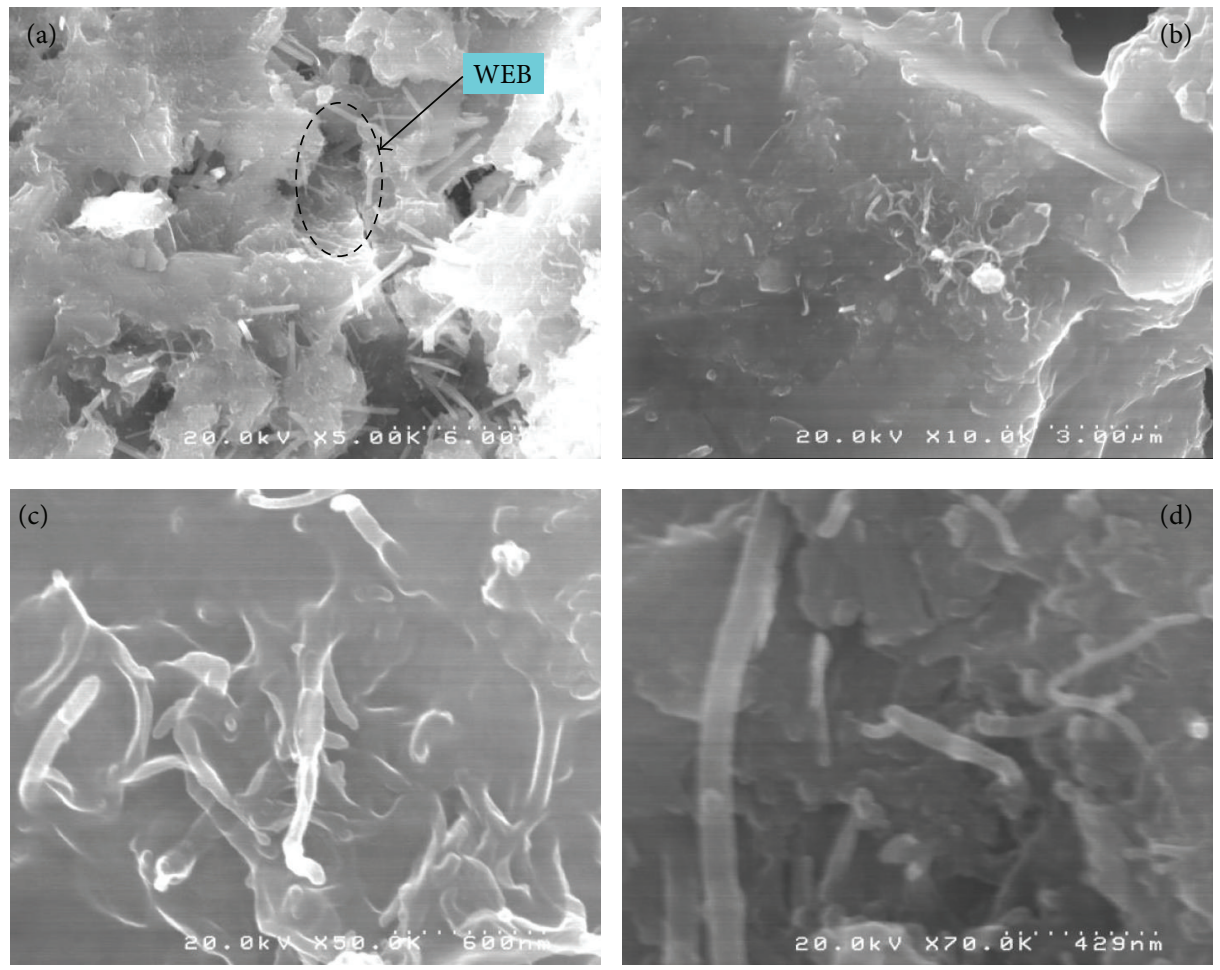

CN4 (5000/10.000/50.000/70.000 times)
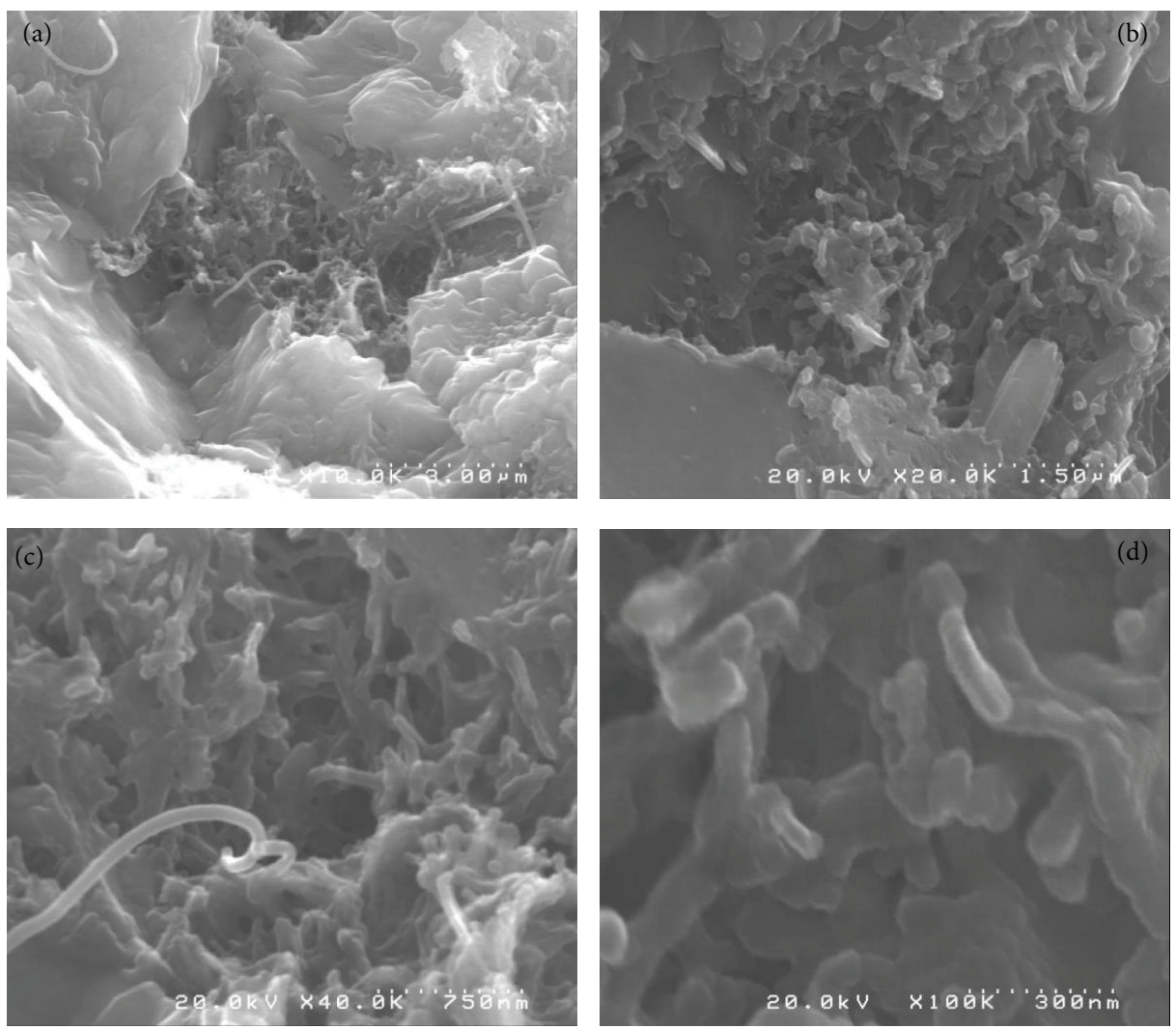

CN6 (10.000/20.000/40.000/100.000 times)

FIGURE 18: SEM images of samples CN4 and CN6. 
nanomaterials in construction can represent savings and greater profitability in the enterprises, as well as a positive step towards preserving the environment when using Portland cement in a more efficient and durable in concrete structures.

\section{References}

[1] B. Addis, Building: 3000 Years of Design Engineering and Construction, Phaidon, 2007.

[2] M. S. Morsy, S. H. Alsayed, and M. Aqel, "Hybrid effect of carbon nanotube and nano-clay on physico-mechanical properties of cement mortar," Construction and Building Materials, vol. 25, no. 1, pp. 145-149, 2011.

[3] P. Balaguru and K. Chong, Nanotechnology of Concrete: Recent Developments and Future Perspectives, American Concrete Institute, 2008.

[4] C. Fava, L. Bergol, G. Fornasier et al., "Fracture behaviour of self compacting concrete," in Proceedings of the 3rd International RILEM Symposium on Self-Compacting Concrete, pp. 628-636, RILEM Publications SARL, Reykjavik, Iceland, 2003.

[5] D. Gann, A Review of Nanotechnology and Its Potential Applications for Construction, University of Sussex, 2002.

[6] F. Collins, J. Lambert, and W. H. Duan, "The influences of admixtures on the dispersion, workability, and strength of carbon nanotube-OPC paste mixtures," Cement and Concrete Composites, vol. 34, no. 2, pp. 201-207, 2012.

[7] G. Chae and K. Liu, Carbon Nanotubes-Properties and Applications, Edited by J. Michael, Taylor \& Francis Group, Boca Raton, Fla, USA, 2006.

[8] M. Markar and J. Beaudoin, "Carbon nanotubes and their application in the construction industry," in Proceedings of the 1st International Symposium on Nanotechnology in Construction, 2003.

[9] V. Popov, "Carbon nanotubes: properties and application," Materials Science and Engineering R, vol. 43, no. 3, pp. 61-102, 2004.

[10] J. Morais, Aplicações da Nanotecnologia na Indústria da Construção: Análise Experimental em Produtos Cimentícios com Nanotubos de Carbono [Ph.D. thesis], Universidade Federal Fluminense, Rio de Janeiro, Brazil, 2012.

[11] D. C. Montgomery, Introduction to Statistical Quality Control, John Wiley \& Sons, 5th edition, 2005.

[12] G. Hüsken and H. Brouwers, "A new mix design concept for earth-moist concrete: a theoretical and experimental study," Cement and Concrete Research, vol. 38, no. 10, pp. 1246-1259, 2008.

[13] T. Finch, Non-Destructive Testing in Building Services -A General Introduction, BSRIA-Building Services Research and Information Association, 1985.

[14] A. Lorenzi, L. F. Caetano, and M. Drunn, Ultrasound Pulse Velocity Analysis in Concrete Specimens, UFRGS, Rio Grande do Sul, Brazil, 2007.

[15] A. Lorenzi, L. F. Caetano, and M. T. Drunn, Drunn Utilização de Ultrassom para o Monitoramento de Estruturas de Concreto, UFRGS, Rio Grande do Sul, Brazil, 2003.

[16] M. S. Konsta-Gdoutos, Z. S. Metaxa, and S. P. Shah, "Highly dispersed carbon nanotube reinforced cement based materials," Cement and Concrete Research, vol. 40, no. 7, pp. 1052-1059, 2010.
[17] J. Jawed, J. Skalny, and F. Young, Hydration of Portland Cement, Structure and Performance of Cements, Applied Science Publishers, Essex, UK, 1983.

[18] G. Y. Li, P. M. Wang, and X. Zhao, "Mechanical behavior and microstructure of cement composites incorporating surfacetreated multi-walled carbon nanotubes," Carbon, vol. 43, no. 6 , pp. 1239-1245, 2005.

[19] R. Batiston, Estudo exploratório dos efeitos de nanotubos de carbono em matrizes de cimento Portland, Universidade Federal de Santa Catarina, Santa Catarina, Brazil, 2007.

[20] C. Dyke and M. Tour, Functionalized Carbon Nanotubes in Composites, Edited by J. Michael, Taylor \& Francis Group, Boca Raton, Fla, USA, 2006.

[21] D. Brandon and W. Kaplan, Microstructural Characterization of Materials, John Wiley \& Sons, 2008.

[22] T. Nochaiya and A. Chaipanich, "Behavior of multi-walled carbon nanotubes on the porosity and microstructure of cementbased materials," Applied Surface Science, vol. 257, no. 6, pp. 1941-1945, 2011. 

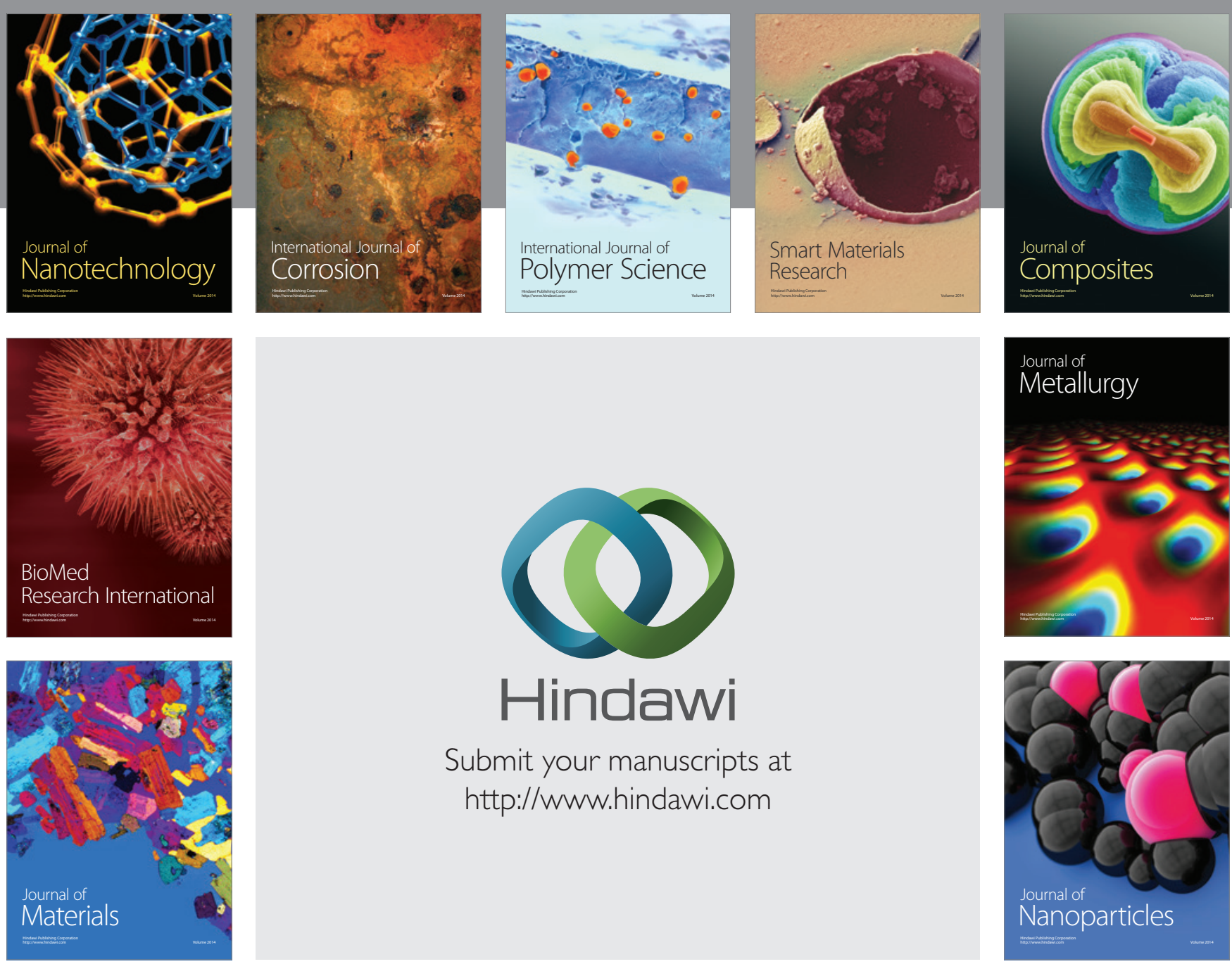

Submit your manuscripts at http://www.hindawi.com
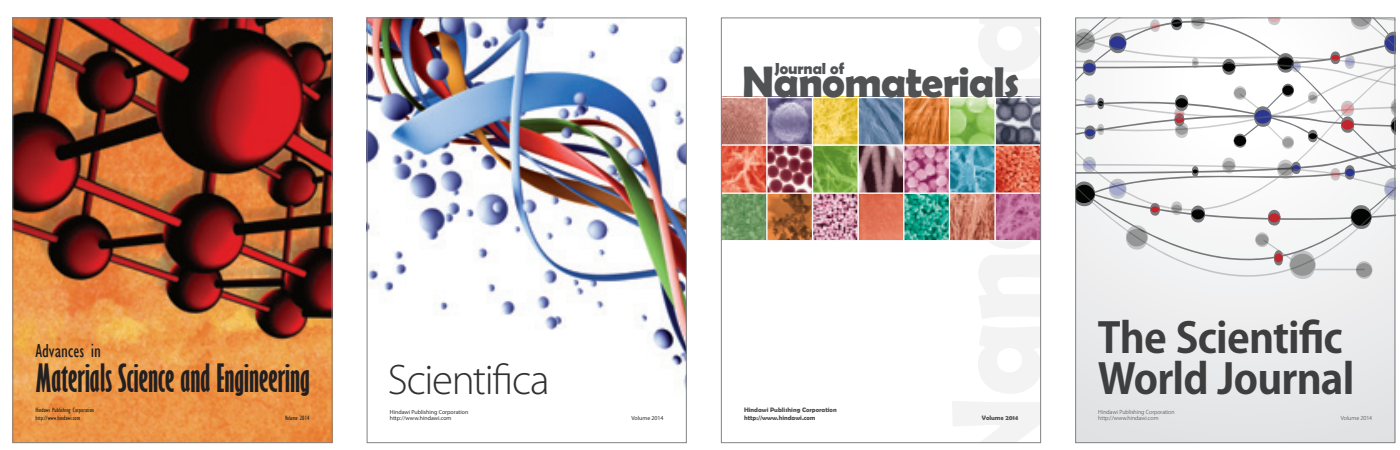

\section{The Scientific World Journal}
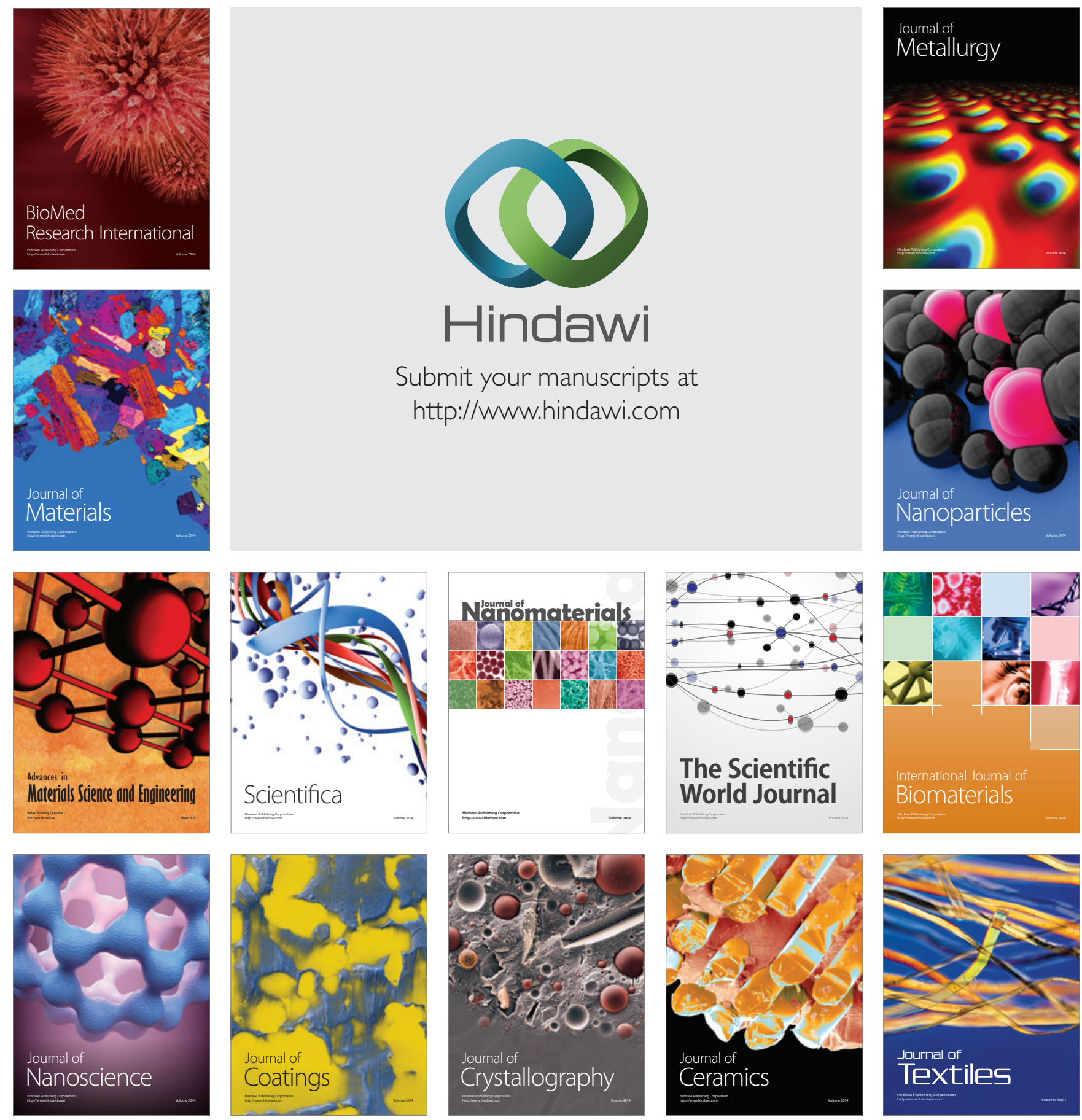